OPEN ACCESS

Edited by:

Hector A. Cabrera-Fuentes, University of Giessen, Germany

Reviewed by:

Luiza Iuliana Hernandez, Linköping University, Sweden Arun Samidurai,

Virginia Commonwealth University, United States

*Correspondence: Elena L. Chernolovskaya elena_ch@niboch.nsc.ru

Specialty section: This article was submitted to Translational Pharmacology, a section of the journal Frontiers in Pharmacology

Received: 04 February 2019 Accepted: 08 April 2019 Published: 26 April 2019

Citation:

Chernikov IV, Vlassov W and Chernolovskaya EL (2019) Current Development of siRNA Bioconjugates:

From Research to the Clinic.

Front. Pharmacol. 10:444. doi: 10.3389/fphar.2019.00444

\section{Current Development of siRNA Bioconjugates: From Research to the Clinic}

\author{
Ivan V. Chernikov, Valentin V. Vlassov and Elena L. Chernolovskaya* \\ Laboratory of Nucleic Acids Biochemistry, Institute of Chemical Biology and Fundamental Medicine, Siberian Branch of the \\ Russian Academy of Sciences, Novosibirsk, Russia
}

Small interfering RNAs (siRNAs) acting via RNA interference mechanisms are able to recognize a homologous mRNA sequence in the cell and induce its degradation. The main problems in the development of siRNA-based drugs for therapeutic use are the low efficiency of siRNA delivery to target cells and the degradation of siRNAs by nucleases in biological fluids. Various approaches have been proposed to solve the problem of siRNA delivery in vivo (e.g., viruses, cationic lipids, polymers, nanoparticles), but all have limitations for therapeutic use. One of the most promising approaches to solve the problem of siRNA delivery to target cells is bioconjugation; i.e., the covalent connection of siRNAs with biogenic molecules (lipophilic molecules, antibodies, aptamers, ligands, peptides, or polymers). Bioconjugates are "ideal nanoparticles" since they do not need a positive charge to form complexes, are less toxic, and are less effectively recognized by components of the immune system because of their small size. This review is focused on strategies and principles for constructing siRNA bioconjugates for in vivo use.

Keywords: RNAi, siRNA, bioconjugate, chemical modifications, patterns of chemical modifications

\section{INTRODUCTION}

Small interfering RNAs (siRNAs) are the most promising type of RNA-based therapeutic oligonucleotide drug, since their mechanism of action is catalytic and each siRNA molecule can inactivate several target RNA molecules in a sequence-specific manner. Since the discovery of RNA interference (RNAi) and the development of the first oligomeric RNAs that trigger RNAi in mammalian cells, significant progress has been made in the development of therapeutic siRNAs (Fire et al., 1998; Crooke et al., 2018). Chemical modifications of RNA have been developed that modulate their activity and stabilize them in biological fluids (Hoerter and Walter, 2007); some progress has been made in the development of methods for the delivery of siRNAs to cells (Hassler et al., 2018). Several siRNA-based drugs are undergoing clinical trials, and one drug patisiran (Onpattro) is approved for use in the clinic (Garber, 2018). However, the outstanding potential of siRNAs as therapeutic drugs has not yet been fully implemented. A number of unsolved problems remain: it is essential to develop an effective means of delivering siRNAs to certain types of cells; it is also necessary to create modified versions of siRNAs that are stable, effectively silence target RNAs, and do not cause side effects. These problems are a consequence of the properties of siRNAs, which are large, polyanionic molecules that are unstable in biological media and are capable of causing unwanted immune responses when they enter cells. 


\section{RNAi}

Induction of RNAi occurs when double-stranded RNA (dsRNA) enters the cell; e.g., when transfected with dsRNA, infected with RNA-containing viruses (De Paula et al., 2007), or when endogenously formed in cells as a result of transposon or non-coding RNA expression (Khvorova et al., 2003). Mechanism of RNAi is divided in to two phases: in the first stage (initiation phase), long dsRNA is cleaved by the endoribonuclease Dicer into siRNAs, short dsRNAs (21-23 bp) with two nucleotides protruding at the $3^{\prime}$-ends. In the second stage (effector phase), the multiprotein RNA-induced silencing complex (RISC) is formed, which, after activation, performs recognition and sequence-specific cleavage of the target mRNA
(Figure 1). It has been shown that RNAi in mammalian cells can be induced by chemically or enzymatically synthesized siRNAs that mimic dsRNA Dicer cleavage products (Nakanishi, 2016); in this case, the RNAi mechanism involves only the effector phase.

In the first stage of RISC assembly, the R2D2 protein (in Drosophila) or its analog (in other species), which contains two dsRNA binding domains and the Dicer binding domain, binds the siRNA. R2D2 recognizes and binds the thermodynamically more stable $5^{\prime}$ end of the duplex, which allows further binding of Dicer (Tomari et al., 2004), whose dsRNA-binding domain has specificity for 3 '-overhangs (Ma et al., 2004). Thus, the intermediate RISC loading complex (RLC) is formed. Following formation of the RLC, Dicer interacts with argonaute- 2

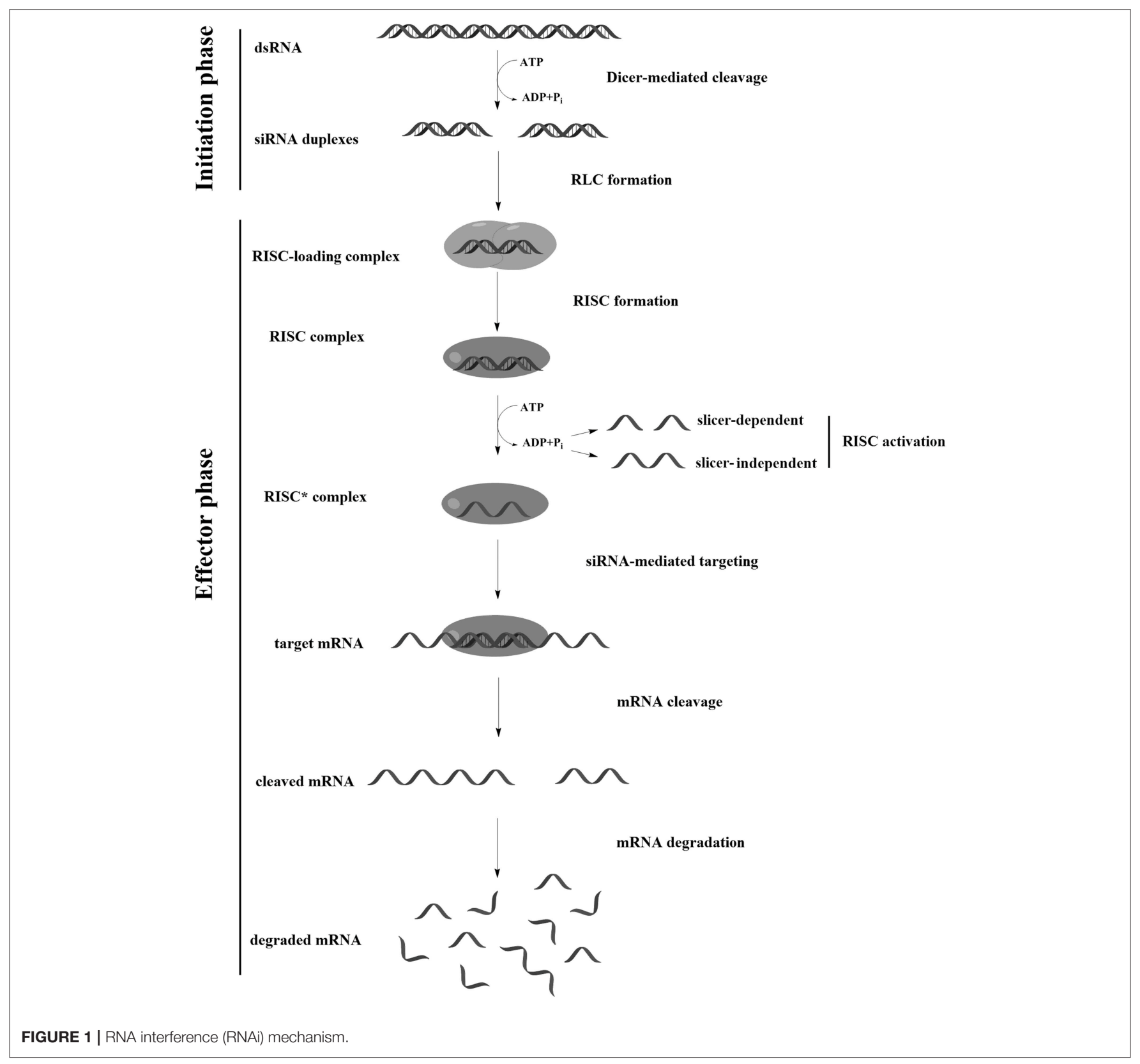


(Ago2), presumably with the participation of the PAZ domains (Bernstein et al., 2001).

At the last stage of RISC assembly, Ago2 cuts and causes dissociation of one of the siRNA strands ("passenger strand"), resulting in the formation of an activated RISC*. Ago2 and the remaining siRNA strand ("guide strand") are the main components of activated RISC (Aronin, 2006; Addepalli et al., 2010); however, a number of other proteins may also be part of this complex (Rana, 2007; Ohrt et al., 2008). The selection of the strand that is included in RISC* is determined by the orientation of the Dicer-R2D2 heterodimer relative to the siRNA; since R2D2 interacts with the thermodynamically more stable end of the duplex, the most active siRNAs are those with a $5^{\prime}$ end of the sense strand more thermostable than the $5^{\prime}$ end of the antisense strand. Ago 2 cuts both the siRNA passenger strand and the target mRNA (Liu et al., 2004); however, siRNA strand dissociation can be carried out without cleavage. Moreover, it is assumed that human Ago2 causes strand dissociation, mainly by a mechanism that does not require its cleavage (Muhonen et al., 2007; Park and Shin, 2015), therefore, the total melting point of the duplex can contribute to the efficiency of siRNA interfering activity. Recognition of the mRNA target by RISC* occurs in several stages, wherein the "seed" region (the siRNA region from 2 to 8 nucleotides from the $5^{\prime}$ end of antisense strand) plays an important role. First, an initial screening of the sequence for three nucleotides (2-4 nucleotides from the $5^{\prime}$ end of the siRNA strand) occurs (Chandradoss et al., 2015). After the triplet is recognized, the fifth nucleotide from the $5^{\prime}$ end of the antisense strand interacts with the target mRNA, which contributes to conformational changes, opening nucleotides 6-8 and 13-16 for interaction (Schirle et al., 2014). The complementary interaction of the siRNA strand with the mRNA provides an advantageous conformation to cleave the mRNA between nucleotides 1011 relative to the $5^{\prime}$ end of the siRNA, which occurs via the PIWI domain of Ago2 (Jinek and Doudna, 2009). After cutting and dissociating from the complex, the target RNA and passenger strand of the siRNA are degraded by ribonucleases. Released RISC* can participate in subsequent cycles of cleavage in a catalytic manner (Haley and Zamore, 2004; Aronin, 2006; Leuschner et al., 2006).

Due to the high affinity of RISC* to single-stranded RNA, binding efficiency of RISC* with the target mRNA is almost an order of magnitude greater than that of antisense oligodeoxynucleotides (ASOs) with the same sequence in which binding to the target mRNA occurs only through complementary interaction (Ameres et al., 2007). Thus, the concentration of siRNA at which an effective decrease in the expression of the target gene is observed is two to three orders of magnitude lower compared to antisense oligonucleotides (Lemaitre et al., 1987; Subramanian et al., 2015).

\section{BARRIERS FOR SIRNA TO THEIR TARGETS}

There are a number of biological barriers that impede the effective action of RNA in mammalian cells. First, since siRNAs are polyanions, they are unable to penetrate directly through the hydrophobic cell membrane and can enter the cell only by endocytosis or pinocytosis. However, in order to implement the silencing effect, endocytosed siRNA must penetrate the endosome membrane and exit into the cytoplasm, otherwise it will undergo cleavage by ribonucleases (Varkouhi et al., 2011), or will leave the cell via exocytosis (Shukla et al., 2016). When siRNA enters the cytoplasmic space, it can also be cleaved by cytoplasmic ribonucleases (Whitehead et al., 2009) or its concentration can decrease due to the division of target cells.

Despite the high specificity of the action, some siRNA can cause a number of non-targeted effects that prevent its use in high concentrations due to the toxicity they cause. The most significant non-targeted effect of siRNA is unwanted activation of the system of innate immunity under the action of certain motifs in the siRNA sequence. When interacting with the membrane surface or in the endosome, immunostimulating motifs can be recognized by Toll-like receptors (TLR3/7/8) (Oosenbrug et al., 2017; Pirher et al., 2017), inducing the production of interferons $(\alpha$ or $\beta$ ) and inflammatory cytokines that activate immune response and induce global changes in gene expression pattern (Mansoori et al., 2016). Other non-target effect of siRNAs is the displacement of endogenous micro-RNA from RISC, which can disrupt the natural regulation pathways in the cell. Also, the sense strand can be introduced in RISC* and suppress the expression of non-target genes, similar effects can be caused by the antisense strand of siRNA which bind to partially homologous non-target mRNA. In last case the block of translation does not include the cleavage of mRNA (Huntzinger and Izaurralde, 2011).

In the transition to the level of the organism, there are new factors that reduce the effectiveness of the siRNA, such as: siRNA filtration by the kidneys, siRNA capture by immune cells, cleavage by serum ribonucleases, the endothelial barrier (Kanasty et al., 2012, p. 511). Due to the presence of these barriers, siRNA have reduced bioavailability and unfavorable pharmacokinetics in vivo, which necessitates the use of high doses of siRNA and makes it not always possible to achieve the desired effect. This review examines approaches to solving the above problems based on chemical modifications of siRNAs; namely, introducing unnatural nucleotides into the siRNA structure and attaching molecules to siRNAs, ensuring the interaction of conjugates with biological structures that increase the efficiency and specificity of siRNAs as potential drugs.

\section{CHEMICAL MODIFICATIONS OF SIRNA}

Chemical modifications may affect the properties of siRNA: sensitivity to ribonucleases, recognition by the RNAi system, hydrophobicity, toxicity, duplex melting temperature, and conformation of the RNA helix (Manoharan, 2004; Behlke, 2008; Chen et al., 2018). Modifications can be divided into modifications of ribose, phosphates, and nucleobases (Table 1; Figure 2). Each type of modification is reviewed separately below.

\section{Ribose Modifications}

Among all ribose modifications, substitutions in the 2'-position most effectively protect siRNAs against the action of serum nucleases, as the $2^{\prime} \mathrm{OH}$ group participates in the cleavage of 
TABLE 1 | The effect of chemical modifications on siRNA properties.

\begin{tabular}{|c|c|c|c|c|}
\hline Modification & Structure & $\begin{array}{c}{ }_{\Delta} T_{m} \text { duplex per } \\
\text { modi-fication }\end{array}$ & Impact on the efficiency of RNAi & $\begin{array}{l}\text { Other properties of modification (effect on } \\
\text { ribose conformation, nuclease resistance, } \\
\text { toxicity, etc.) }\end{array}$ \\
\hline
\end{tabular}

\section{SUGAR MODIFICATIONS}

2'-O-methyl (2'O-Me)

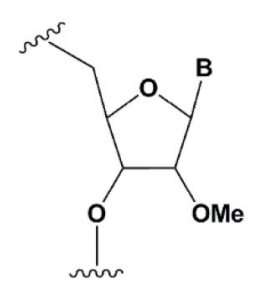

$+0.5-1.5^{\circ} \mathrm{C}$

Pro

or more consecutive 2'O-Me

inhibits RNAi (Czauderna et al., 2003:

Prakash et al., 2005; Akinc et al.,

2008; Manoharan et al., 2011).

However, siRNAs possessing

biological activity, containing $75-82 \%$

2' $\mathrm{O}-\mathrm{Me}$, are described (Ray et al.,

2017; Foster et al., 2018).
Stabilizes $3^{\prime}$ endo ribose conformation.

$\geq 5-30 \%$ of $2^{\prime} \mathrm{O}-\mathrm{Me}$ increase nuclease resistance in vitro (Jackson et al., 2006; Volkov et al., 2009; Petrova Kruglova et al., 2010; Takahashi et al., 2012) and in vivo (Liu et al., 2014; Chernikov et al., 2017). $2^{\prime} \mathrm{O}-\mathrm{Me}$ analogs of $\mathrm{A}, \mathrm{G}$ and $\mathrm{U}$ reduce the immune response (Judge et al., 2006).

\section{$2^{\prime}$-fluoro $\left(2^{\prime} \mathrm{F}\right)$}<smiles>[B]CC1OC([B])C(OC)C1F</smiles>

$2^{\prime} \mathrm{F}$ analogs in all siRNA positions only slightly reduces the activity of RNAi (Deleavey et al., 2010).

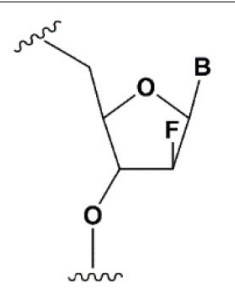

$+1.2^{\circ} \mathrm{C}$

$100 \%$ 2'FANA in the sense chain reduce the efficiency of RNAi. $\geq 30 \%$ 2'FANA in the antisense chain inhibits RNAi (Dowler et al., 2006; Deleavey et al., 2010).

Stabilizes $3^{\prime}$ endo ribose conformation. $\geq 50 \% 2^{\prime} \mathrm{F}$ increase nuclease resistance in vitro (Cuellar et al., 2014) and in vivo (Viel et al., 2008; Manoharan et al., 2011).

$2^{\prime} \mathrm{F}$ analogs of adenine $(\geq 7 \%)$ reduce the immune response in vitro (Fucini et al., 2012). $>50 \%$ of the $2^{\prime} \mathrm{F}$ in siRNA may cause toxicity (Ohrt and Schwille, 2008; Shen et al., 2015; Garber, 2016).

Stabilizes $2^{\prime}$ endo ribose conformation. $\geq 50 \%$ 2'FANA increases nuclease resistance in vitro (Deleavey et al., 2010); more effectively than $2^{\prime} \mathrm{F}$ protect siRNA from the action of exoribonucleases (Damha et al., 2001).

\section{2'-O-methoxyethyl} (2'O-MOE)

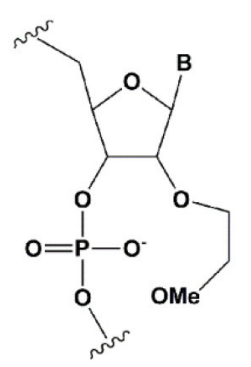

Locked nucleic acid (LNA)

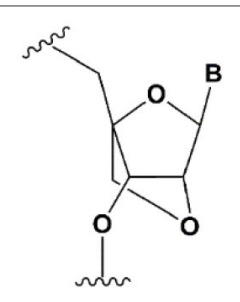

Unlocked nucleic acid (UNA)

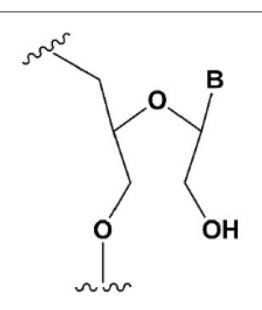

$+0.9-1.7^{\circ} \mathrm{C}$

$2^{\prime}-\mathrm{MOE}$ at the flanks of the sense strand and the central part (6-11) of the antisense strand are tolerable for RNAi (Prakash et al., 2005;

Manoharan et al., 2011).

Replacement of 9th or 10th nucleotides from the $5^{\prime}$ end to 2'O-MOE analogs of nucleotide increases the probability of entry in RISC (Song et al., 2017).

$\geq 40 \%$ LNA in the sense chain inhibit RNAi by 5-20\% (Elmen et al., 2005). $>20 \%$ LNA in the antisense chain, or the first LNA nucleotide at the $5^{\prime}$ end completely inhibit RNA (Braasch et al., 2003; Elmen et al., 2005; Mook et al., 2007; Schyth et al., 2012). LNA can change thermal asymmetry of the duplex, increasing the efficiency of siRNA (Elmen et al., 2005).

$>15 \%$ UNA inhibit RNAi (Laursen
et al., 2010).

UNA can change thermal asymmetry of the duplex, increasing the efficiency of siRNA (Mook et al., 2010; Vaish et al., 2011; Snead et al., 2013).
Stabilizes $3^{\prime}$ endo ribose conformation. $\geq 15 \% 2^{\prime} \mathrm{O}-\mathrm{MOE}$ at the ends of the siRNA sense chain increases nuclease resistance in vitro (Lima et al., 2012).
Reduces the conformational flexibility of nucleotides, fixing the $\mathrm{C}^{\prime}$ endo conformation of the ribose (Julien et al., 2008). $\geq 10-20 \%$ LNA in siRNAs increase nuclease resistance in vitro (Elmen et al., 2005) and in vivo (Mook et al., 2010).
Increases conformational flexibility of nucleotides and reduces the melting point of the duplex.

UNA at the $3^{\prime}$ ends of the duplex protect siRNA from $3^{\prime}$ exoribonucleases in vitro and in vivo (Laursen et al., 2010; Mook et al., 2010; Pasternak and Wengel, 2011). 
TABLE 1 | Continued

\begin{tabular}{|c|c|c|c|c|}
\hline Modification & Structure & $\begin{array}{l}\Delta T_{m} \text { duplex per } \\
\text { modi-fication }\end{array}$ & Impact on the efficiency of RNAi & $\begin{array}{l}\text { Other properties of modification (effect on } \\
\text { ribose conformation, nuclease resistance, } \\
\text { toxicity, etc.) }\end{array}$ \\
\hline 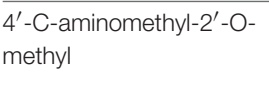 & & $-1^{\circ} \mathrm{C}$ & $\begin{array}{l}>2 \text { analogs in the sense or }>1 \text { analog } \\
\text { in the antisense strand inhibit RNAi } \\
\text { (Gore et al., 2012). }\end{array}$ & $\begin{array}{l}\geq 2 \text { modifications at the } 3^{\prime} \text { ends increase } \\
\text { nuclease resistance in vitro (Gore et al., 2012). }\end{array}$ \\
\hline $\begin{array}{l}\text { Deoxyribonucleotide } \\
\text { (dNMP) }\end{array}$ & & $-0.5^{\circ} \mathrm{C}$ & $\begin{array}{l}>50 \% \text { dNMP inhibits RNAi (Parrish } \\
\text { et al., 2000; Elbashir et al., 2001; } \\
\text { Ui-Tei et al., 2008). } \\
\text { dNMP can change thermal } \\
\text { asymmetry of the duplex, increasing } \\
\text { the efficiency of siRNA in vitro (Ui-Tei } \\
\text { et al., 2008). }\end{array}$ & $\begin{array}{l}\text { Protects against exoribonucleases (Parrish } \\
\text { et al., 2000). }\end{array}$ \\
\hline $\begin{array}{l}\text { Cyclohexenyl nucleic } \\
\text { acids (CeNA) }\end{array}$ & & $+1.5^{\circ} \mathrm{C}$ & $\begin{array}{l}\text { 5\% CeNA in siRNA are tolerated by } \\
\text { RNAi (Herdewijn and Juliano, 2007; } \\
\text { Nauwelaerts et al., 2007). } \\
\text { CeNA can change thermal asymmetry } \\
\text { of the duplex, increasing the efficiency } \\
\text { of siRNA in vitro (Herdewijn and } \\
\text { Juliano, 2007; Fisher et al., 2009). }\end{array}$ & $\begin{array}{l}\text { Stabilizes } 3^{\prime} \text { endo ribose conformation (Ovaere } \\
\text { et al., 2011). } \\
\geq 25 \% \text { CeNA analogs increase serum nuclease } \\
\text { resistance (Wang et al., 2001). }\end{array}$ \\
\hline \multicolumn{5}{|c|}{ PHOSPHATE BACKBONE MODIFICATIONS } \\
\hline Phosphorothioate (PS) & & $-0.7^{\circ} \mathrm{C}$ & $\begin{array}{l}\text { PS inhibits RNAi when introduced in } \\
\text { the central part of the antisense } \\
\text { strand (Amarzguioui et al., 2003; } \\
\text { Schwarz et al., 2004; Prakash et al., } \\
\text { 2005; Eckstein, 2014). }\end{array}$ & $\begin{array}{l}\text { PS protects siRNAs from the action of } \\
\text { exoribonucleases in vitro and in vivo } \\
\text { (Soutschek et al., 2004). } \\
>50 \% \text { PS cause toxicity in vitro (Harborth } \\
\text { et al., 2003) and in vivo (Henry et al., 2002; } \\
\text { lannitti et al., 2014). }\end{array}$ \\
\hline
\end{tabular}


TABLE 1 | Continued

\begin{tabular}{|c|c|c|c|c|}
\hline Modification & Structure & $\begin{array}{l}{ }_{\Delta} T_{m} \text { duplex per } \\
\text { modi-fication }\end{array}$ & Impact on the efficiency of RNAi & $\begin{array}{l}\text { Other properties of modification (effect on } \\
\text { ribose conformation, nuclease resistance, } \\
\text { toxicity, etc.) }\end{array}$ \\
\hline $\begin{array}{l}\text { Tert-butyl-S-acyl-2- } \\
\text { thioethyl } \\
\text { (tBu-SATE) }\end{array}$ & & No data. & $\begin{array}{l}\text { 25\% tBu-SATE are tolerated by RNAi } \\
\text { (Meade et al., 2014). }\end{array}$ & $\begin{array}{l}\geq 20-40 \% \text { tBu-SATE in siRNA increase } \\
\text { nuclease resistance in vitro and in vivo (Meade } \\
\text { et al., 2014). } \\
\text { Increases hydrophobicity of siRNA. Cleaved by } \\
\text { thioesterase in the cytoplasm of the cell giving } \\
\text { a phosphodiester bond (Meade et al., 2014). }\end{array}$ \\
\hline Boranophosphate (BP) & & $\begin{array}{l}+0.4-1^{\circ} \mathrm{C}(<50 \% \text { of } \\
\text { siRNA }) \\
-0.8-2.5^{\circ} \mathrm{C}(>50 \% \\
\text { of } \operatorname{siRNA})\end{array}$ & $\begin{array}{l}>50 \% \text { PB inhibit RNAi, the central } \\
\text { part of the antisense strand is the } \\
\text { most sensitive to modifications (Hall } \\
\text { et al., 2004). }\end{array}$ & $\begin{array}{l}\text { Approximately two times more effectively } \\
\text { protect against ribonucleases than PS, but do } \\
\text { not cause toxicity in vitro (Hall et al., 2004, } \\
\text { 2006). }\end{array}$ \\
\hline Amide linker & & -0.3 to $+0.9^{\circ} \mathrm{C}$ & $\begin{array}{l}\text { In some siRNA positions, a single } \\
\text { substitution for an amide linker is } \\
\text { tolerated by RNAi (Mutisya et al., } \\
\text { 2017). }\end{array}$ & $\begin{array}{l}\text { The introduction of two amide linkers from the } \\
3^{\prime} \text { ends of the duplex increases the nuclease } \\
\text { resistance of siRNA in serum (Iwase et al., } \\
\text { 2007; Selvam et al., 2011). }\end{array}$ \\
\hline
\end{tabular}

\section{$5^{\prime}$-PHOSPHATE MODIFICATIONS}

$5^{\prime} \mathrm{C}$-methyl (S-isomer)

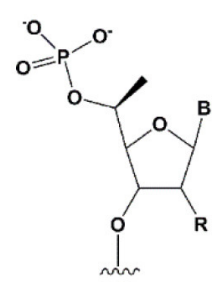

$-3.2^{\circ} \mathrm{C}$

One $(S) 5^{\prime} C$-methyl at the $5^{\prime}$ end of the antisense strand is tolerated by RNAi (Prakash et al., 2015).
(S) $5^{\prime}$ C-methyl protect siRNA from exonucleases two times more efficiently than PS (Kel'in et al., 2016).

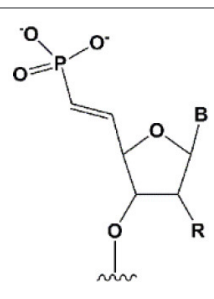

$5^{\prime}(E)$-vinylphosphonate 2-folds improves siRNA interaction efficiency with Ago2 (Elkayam et al., 2017). Does not change the biological activity of siRNA in vitro (Haraszti et al., 2017).
Stabilizes $5^{\prime}$ phosphate, protect from the action of phosphatases and exonucleases. Improves the pharmacokinetics (Elkayam et al., 2017; Haraszti et al., 2017). 
TABLE 1 | Continued

\begin{tabular}{|c|c|c|c|c|}
\hline Modification & Structure & $\begin{array}{l}{ }_{\Delta} T_{m} \text { duplex per } \\
\text { modi-fication }\end{array}$ & Impact on the efficiency of RNAi & $\begin{array}{l}\text { Other properties of modification (effect on } \\
\text { ribose conformation, nuclease resistance, } \\
\text { toxicity, etc.) }\end{array}$ \\
\hline \multicolumn{5}{|l|}{ BASE MODIFICATIONS } \\
\hline $2^{\prime}$ thiouridine $\left(s^{2} U\right)$ & $\mathbf{R}$ & $0-2^{\circ} \mathrm{C}$ & $\begin{array}{l}7 \% s^{2} \cup \text { are tolerated by RNAi (Sipa } \\
\text { et al., 2007). } \\
s^{2} \cup \text { can change thermal asymmetry } \\
\text { of the duplex, increasing the efficiency } \\
\text { of siRNA in vitro (Sipa et al., 2007; } \\
\text { Peacock et al., 2011). }\end{array}$ & $\begin{array}{l}s^{2} U \text { slightly increases nuclease resistance } \\
\text { in vitro. }\end{array}$ \\
\hline Pseudouridine $(\Psi)$ & & -1 to $+1^{\circ} \mathrm{C}$ & $\begin{array}{l}\text { One } \Psi \text { is tolerated by RNA(Sipa et al., } \\
\text { 2007). }\end{array}$ & $\begin{array}{l}\text { Stabilizes } 3^{\prime} \text { endo ribose conformation. } \\
\text { Reduces the PKR-induced interferon response } \\
\text { (Anderson et al., 2010). }\end{array}$ \\
\hline
\end{tabular}<smiles>[B]C(OC)[C@H](OC)[C@@](C)(OP(=O)([O-])OC)[C@@H](C)OC</smiles>

RNA by endoribonucleases (Findlay et al., 1962; Breslow and Chapman, 1996). In this case, the size of the substituent at the 2'-position of ribose affects the properties of the modified base. When the hydrogen of the $2^{\prime} \mathrm{OH}$ group is replaced with a relatively small methyl residue (2'-O-methyl modification $\left[2^{\prime} \mathrm{O}\right.$ Me]) (Bobst et al., 1969), there is stabilization of the $3^{\prime}$-endo ribose conformation, which provides the A-type RNA helix essential for RNAi. The introduction of $2^{\prime} \mathrm{O}-\mathrm{Me}$ modifications into siRNA promotes its protection against nucleases both in vitro (Volkov et al., 2009) and in vivo (Liu et al., 2014; Chernikov et al., 2017). Moreover, the introduction of these modifications reduces the immune response (Judge et al., 2006). These properties make $2^{\prime} \mathrm{O}-\mathrm{Me}$ modification of siRNA one of the most attractive strategies for introducing siRNA-based drugs into the clinic (Khvorova, 2017; Ray et al., 2017). However, replacement of each nucleotide in the siRNA with a $2^{\prime} \mathrm{O}-\mathrm{Me}$ 
modified one leads to inhibition of RNAi (Czauderna et al., 2003); even the replacement of $50 \%$ of the nucleotides in siRNAs with $2^{\prime} \mathrm{O}-\mathrm{Me}$ could inhibit this process. The presence of a hydrophobic residue at the $2^{\prime}$ position alters the overall structure of siRNA and increases the thermal stability of the duplex, which interferes with its effective incorporation into RISC and dissociation of the passenger strand.

Since the size of the modification may contribute to an increase in the nuclease resistance of siRNA (Cummins et al., 1995), attempts have been made to introduce more voluminous substituents into the $2^{\prime}$ position of ribose (2'-O-methoxyethyl [2'O-MOE] Prakash et al., 2005; Zanardi et al., 2018, 2'Oallyl Amarzguioui et al., 2003, 2'O-benzyl Kenski et al., 2012, and other modifications); however, these substitutions more significantly inhibited RNAi than $2^{\prime} \mathrm{O}-\mathrm{Me}$.

Among the large number of bulky $2^{\prime}$ substituents, the $2^{\prime} \mathrm{O}$ MOE ribose is one of the few modifications that stabilizes the $3^{\prime}$ endo ribose conformation and increases the melting temperature of the duplex more effectively than 2'O-Me (Dorn et al., 2004). The introduction of $2^{\prime} \mathrm{O}-\mathrm{MOE}$ into siRNA without inhibiting RNAi is possible only along the flanks of the duplex and the central part of the antisense strand (Prakash et al., 2005). Availability of $2^{\prime} \mathrm{O}-\mathrm{MOE}$ in the central part of the antisense strand (9 or 10 nucleotides) was recently shown to increase the biological activity of siRNA by reducing the probability of inclusion of the sense strand in RISC (Song et al., 2017), although direct confirmation of the mechanism of modified strands selection was not provided. Apparently, the presence of a bulk modification in this position may sterically affect the interaction with a Dicer-R2D2 heterodimer or the formation of RISC (Koller et al., 2006).

Unlike the substitution of hydrogen in the $2^{\prime} \mathrm{OH}$ group, the replacement of oxygen by $2^{\prime}$-fluorine $\left(2^{\prime} \mathrm{F}\right)$ is more consistent with the original structure of RNA, effectively stabilizing the $3^{\prime}$ endo ribose conformation (Manoharan et al., 2011). Introduction of $2^{\prime} \mathrm{F}$ into all nucleotides of the duplex only slightly reduces the efficiency of RNAi (Blidner et al., 2007; Deleavey et al., 2010). This modification protects siRNAs from the action of nucleases in vitro and in vivo (Manoharan et al., 2011; Fucini et al., 2012); however, the introduction of modifications in 50\% of the siRNA nucleotides could lead to toxicity (Shen et al., 2015; Janas et al., 2017). In 2016, the third stage of clinical trials of the Alnylam conjugate of $\mathrm{N}$-acetylgalactosamine and siRNA containing 50\% 2'F revealed its cardiotoxicity (Garber, 2016). Since these effects were not detected in previous stages of clinical trials (Zimmermann et al., 2017) and the toxicity of $2^{\prime} \mathrm{F}$ modified siRNA for the heart was not previously shown, these results may be occasional and not related to the properties of the conjugate. On the other hand, it was shown that under the action of ASO containing 50\% 2'F, the expression profiles of a number of genes in vitro (Shen et al., 2015) and in vivo (Shen et al., 2018) were altered. In confirmation of the toxicity hypothesis of siRNAs containing $2^{\prime} \mathrm{F}$, another study showed that the introduction of $2^{\prime} \mathrm{F}$ at the ends of the duplex alters the localization of siRNA from cytoplasmic to nuclear (Ohrt and Schwille, 2008). These results suggested that only a limited amount (no more than 25\%) of $2^{\prime} \mathrm{F}$ modifications (Ray et al.,
2017) could be introduced for therapeutic applications. However, a decrease in the proportion of $2^{\prime} \mathrm{F}$ analogs from 50 to $25 \%$ did not lead to a decrease in hepatotoxicity in rats and mice following intravenous administration of high doses $(100-200 \mathrm{mg} / \mathrm{kg})$ of siRNA and $\mathrm{N}$-acetylgalactosamine conjugate (Janas et al., 2018).

Although other positions in ribose, such as $4^{\prime}$ carbon, can be modified [4'S Gore et al., 2012, 4'C-aminomethyl-2'-O-methyl Takahashi et al., 2012, and 4'C-O-methyl-2'-O-methyl Harp et al., 2018 (Table 1)] and such modifications protect siRNAs from nucleases in vitro efficiently, these modifications are not widely used in biomedical research because they significantly inhibit RNAi (Deleavey and Damha, 2012).

Ribose modifications are not limited to substitutions in structure; nucleic acid analogs with a modified structure of the furanose cycle, such as derivatives containing 6-membered (hexitol [HNA] Fisher et al., 2009, cyclohexenic [CeNA] Nauwelaerts et al., 2007, and altritol [ANA] Fisher et al., 2007 nucleic acids) and 7-membered rings (oxepanic nucleic acid [ONA] Sabatino and Damha, 2007), bicyclic (locked nucleic acids [LNA] Braasch et al., 2003, 2'-deoxymethanocarbanucleosides [MCs] Terrazas et al., 2011), tricyclic (tricyclo-DNA [tc-DNA] Goyenvalle et al., 2015), and acyclic (unlocked nucleic acid [UNA] Jensen et al., 2008; Langkjaer et al., 2009) derivatives, can protect siRNAs from the action of nucleases and in some cases (CeNA, LNA, and UNA) do not inhibit RNAi (Herdewijn and Juliano, 2007; Deleavey and Damha, 2012). Among the 6-membered nucleic acid derivatives, CeNA is most suitable for modifying siRNA, since its complementary interaction with RNA stabilizes the duplex, increasing the melting point by $1.5^{\circ} \mathrm{C}$ per modified base and increases the oligoribonucleotide resistance to degradation in serum (Wang et al., 2001). Bicyclic derivatives (LNA) can even more significantly increase the melting temperature of siRNA. In the case of LNA, affinity for the complementary strand is increased by $2-8^{\circ} \mathrm{C}$ per nucleotide due to the extra cycle between $2^{\prime}$ and $4^{\prime}$ carbon, which fixes the $3^{\prime}$ endo ribose conformation (Julien et al., 2008). However, the introduction of this modification into siRNA strongly affects its interfering activity and the antisense strand is especially sensitive to this modification; even one LNA modification of its first nucleotide from the $5^{\prime}$ end completely inhibits RNAi (Elmen et al., 2005). Conversely, conformationally more flexible acyclic derivatives, such as UNA or glycolic nucleic acid (GNA), can destabilize the duplex, reducing the melting point by $5-8$ and $5-18^{\circ} \mathrm{C}$ per nucleotide, respectively (Laursen et al., 2010; Schlegel et al., 2017).

Since thermal asymmetry of the duplex makes a primary contribution to "guide" strand selection, modifications stabilizing the duplex formed by the $3^{\prime}$ end of the antisense strand and $5^{\prime}$ end of the sense strand and, conversely, modifications destabilizing the duplex formed by the $3^{\prime}$ end of the sense strand and $5^{\prime}$ end of the antisense strand can increase the efficiency of RNAi by providing favorable duplex thermal asymmetry. Thus, the introduction of LNA, UNA, or GNA at different ends of the duplex can lead to an increase in siRNA efficiency by increasing the probability of incorporation of the antisense strand into RISC (Vaish et al., 2011). Moreover, due the change in thermal asymmetry of siRNA, the probability of incorporation of the 
sense strand in RISC and the following suppression of expression of non-target genes those have regions complementary to the sense strand of the siRNA decreases.

The antisense strand of siRNA can also block the translation of non-target mRNA by complementary interaction with the "seed" region. It has been shown that a decrease in the melting temperature of this region leads to a decrease in the efficiency of suppression of non-target genes (Jackson et al., 2006). Therefore, the introduction of UNA or GNA modifications in the "seed" region of the antisense strand of siRNAs contributes to an increase in the specificity of action (Bramsen et al., 2009; Janas et al., 2017).

An interesting strategy to increase the specificity of the siRNA is introducing nicks in the middle of the sense strand of the siRNA (small internally segmented interfering RNA [sisiRNA]) (Bramsen et al., 2007). sisiRNAs have a greater specificity of biological action because RISC containing sense strand is not formed. sisiRNAs are less stable compared to siRNAs of the same sequence; thus, LNA modifications are introduced to stabilize sisiRNAs. However, it has been shown that such a duplex design did not contribute to a significant increase in the biological activity of siRNA in vitro (Hong and Nam, 2016) or in vivo (Mook et al., 2010).

\section{Phosphate Modifications}

Ribose modifications do not interfere with changes in the phosphate structure, and since that modifications are directly involved in nuclease cleavage (Frazao et al., 2006), it is reasonable that such modifications could effectively protect siRNA from degradation. Replacement of the oxygen of phosphate with sulfur (phosphorothioate [PS] Eckstein, 1970, 2014) or boron (boranophosphate [BP] Hall et al., 2006) has been shown to protect siRNA from the action of ribonucleases in vitro and in vivo (Soutschek et al., 2004). The introduction of PS modifications to both strands of the duplex inhibits RNAi to some extent (Schwarz et al., 2004). However, the introduction of PS modifications into oligonucleotides facilitates their penetration into cells in the absence of transfection agents due to non-specific binding to cell receptors and penetration by clathrin-dependent endocytosis (Wang et al., 2018). On the other hand, due to the non-specific interaction of PS oligonucleotides with serum proteins and cell receptors (Lee et al., 1999), activation of the complement system and leukocyte infiltration of the corresponding organs (Iannitti et al., 2014) may occur. Therefore, for clinical use of siRNA, the number of PS modifications should be reduced to $5-50 \%$, depending on the intended dose of siRNA.

Unlike PS, the introduction of BP into the central part of the antisense strand strongly inhibits the action of RNAi; however, a partially modified pattern (25-75\%) may increase the efficiency of RNAi and resistance to ribonuclease (Hall et al., 2004, 2006). At the same time, according to the work of Hall et al. (2004), where unpublished comparison data of PS and BP modifications of siRNA is mentioned, BP was shown to exhibit approximately twice as effective protection of siRNA from nucleases. If so, this modification could address some of the issues regarding the biomedical use of siRNA. One of the main limitations of the use of BP for siRNA modification is the lack of an optimized method of synthesizing large quantities of BP-modified siRNA; therefore, novel methods must be developed to assess the therapeutic potential of BP-modified siRNAs in vivo.

The introduction of modifications replacing the phosphodiester bond with an amide bond (Selvam et al., 2011) contributes to the protection of siRNA from the action of nucleases (Iwase et al., 2007), but their effect on the efficiency of RNAi is uncertain. The introduction of an amide bond between 10,11, and 12 nucleotides, despite the absence of a phosphodiester bond, has been shown to increase the inhibitory effect of the modified siRNA, presumably due to the formation of additional hydrogen bonds between the amide group and Ago2 (Mutisya et al., 2017).

The presence of phosphate at the $5^{\prime}$ end of the "guide" strand of siRNA is essential for RNAi (Frank et al., 2010), while siRNA with $5^{\prime}$-hydroxyl possesses biological activity, since such siRNA is effectively phosphorylated inside cells (Weitzer and Martinez, 2007). When blocking phosphorylation of the 5'-hydroxyl, siRNA does not exhibit interfering activity (Chen et al., 2008). Chemical modifications of the first nucleotide from the $5^{\prime}$ end of the antisense strand can interfere with intracellular phosphorylation (Allerson et al., 2005; Chen et al., 2008; Kenski et al., 2012); however, the introduction of chemically stable phosphate [5'-(S)-C-methyl (Prakash et al., 2015), 5'-methylphosphonate (Lima et al., 2012), and $5^{\prime}(E)$ vinylphosphonate (Elkayam et al., 2017)] at the $5^{\prime}$ end of the antisense strand can restore activity (Lima et al., 2012; Prakash et al., 2015). The introduction of 5'(E)-vinylphosphonate solves this problem most efficiently. It has been shown that such modification of the antisense strand not only improves binding to Ago2 (Elkayam et al., 2017) 2-fold, but also leads to an increase in the accumulation and stability of siRNA conjugates containing cholesterol (Haraszti et al., 2017) or $\mathrm{N}$-acetylgalactosamine (Elkayam et al., 2017) in the organs of mice following subcutaneous injection. Therefore, $5^{\prime}(E)$ vinylphosphonate modification of the antisense strand is a promising strategy for the development of therapeutic drugs based on siRNA.

\section{Nucleobase Modifications}

Substitutions of nucleobases with various modified analogs [pseudouridine, 2'thiouridine, dihydrouridine (Sipa et al., 2007), 2,4-difluorobenzene (Somoza et al., 2006), 4methylbenzimidazole (Somoza et al., 2008), hypoxanthine (Addepalli et al., 2010), 7-deazaguanin (Eberle et al., 2008), $\mathrm{N}^{2}$-alkyl-8-oxoguanine (Kannan and Burrows, 2011), $\mathrm{N}^{2}$-benzylguanine (Puthenveetil et al., 2006), and 2,6-diaminopurine (Chiu and Rana, 2003)] are designed to increase the thermal stability of the duplex by increasing the efficiency of the formation of hydrogen bonds with complementary nucleotides. However, such modifications reduce the efficiency of RNAi and do not contribute to an increase in siRNA resistance to nuclease action (Peacock et al., 2011). Nucleobase modifications in small amounts (up to 10\%) could reduce immune reactions and improve the thermodynamic siRNA profile (Sipa et al., 2007; Anderson et al., 2010). The presence of such modifications in the 
patterns of chemical modification of siRNA can contribute to the optimization of the therapeutic properties of siRNA; however, this approach has not yet found wide application as similar effects can be obtained by introducing other modifications.

\section{PATTERNS OF CHEMICAL MODIFICATIONS OF SIRNAS}

siRNA is degraded in vivo as a result of its cleavage by endonucleases on pyrimidines (Turner et al., 2007) and exonucleases from both the $3^{\prime}$ and $5^{\prime}$ ends (Hsu and Stevens, 1993; Terrazas et al., 2013); thus, it is essential that siRNAs contain chemical modifications at cleavage sites to improve siRNA nuclease resistance to achieve biological activity of bioconjugates in vivo. However, the introduction of certain chemical modifications in siRNA is limited by inhibition of its interfering activity and toxicity. Thus, the introduction of modifications in siRNA is determined by the balance between the number of modifications sufficient for siRNA to be nontoxic, while retaining interfering activity and nuclease resistance. Introducing the $2^{\prime} \mathrm{O}-\mathrm{Me}$ modification into siRNA can lead to inhibition of RNAi if the siRNA contains more than two consecutive $2^{\prime} \mathrm{O}-\mathrm{Me}$ modifications in a row (Czauderna et al., 2003; Manoharan et al., 2011), while 2'O-Me modification of every second nucleotide does not block RNAi (Czauderna et al., 2003). Thus, an important parameter affecting RNAi is not only the number of introduced modifications, but also their location in the duplex.

One of the approaches to finding a balance between interfering activity and nuclease resistance of siRNA with $2^{\prime} \mathrm{O}$ Me modifications is $2^{\prime} \mathrm{O}$-Me selective modification of nucleasesensitive siRNA sites (Volkov et al., 2009). siRNA is subjected to serum cleavage at pyrimidines (Turner et al., 2007); however, replacing all pyrimidines with $2^{\prime} \mathrm{O}-\mathrm{Me}$ analogs completely inhibits the interfering ability of siRNA (Manoharan et al., 2011). It has been shown that the main sites of siRNA cleavage in serum are generally CA, UA, and UG sites. Introduction of $2^{\prime} \mathrm{O}-\mathrm{Me}$ at these sites will preserve the interfering activity of siRNA, increase serum nuclease resistance (Volkov et al., 2009), and provide longterm suppression of target gene expression (Petrova Kruglova et al., 2010; Chernikov et al., 2017).

The main limitation of the introduction of $2^{\prime} \mathrm{F}$ modifications in siRNA is their toxicity, although siRNA conjugates containing $2^{\prime} \mathrm{F}$ modifications on pyrimidines are protected from the action of ribonucleases and, unlike $2^{\prime} \mathrm{O}-\mathrm{Me}$ (Manoharan et al., 2011), possess biological activity (Wolfrum et al., 2007). The introduction of PS into siRNAs is also limited by the toxicity of the resulting oligonucleotides, and since PS-modified siRNAs have been shown to be highly protected against exoribonucleases (Eckstein, 2014; Kel'in et al., 2016), PS modification is used only to replace two or three terminal nucleotides in siRNA (Soutschek et al., 2004). Most of the other chemical siRNA modifications are primarily introduced along the terminal regions of the duplex for various reasons; e.g., the effect of RNAi on proteins, thermal asymmetry, and protection against nucleases (Deleavey and Damha, 2012). It is important that modifications designed to change the properties of siRNAs that are significant for its therapeutic potential can be used together, complementing one another and ensuring biological activity and siRNA resistance to nucleases more efficiently than each modification separately (Deleavey et al., 2010). Recent studies have used combinations of chemical modifications to achieve maximum effect in vivo.

Since after replacing each second nucleotide with the $2^{\prime} \mathrm{O}$ $\mathrm{Me}$ analog, half of the siRNA molecule is unprotected from the action of nucleases, the introduction of $2^{\prime} \mathrm{F}$ modifications into the unmodified portion of the duplex was proposed. It has been shown that siRNA molecules with alternating $2^{\prime} \mathrm{O}$ $\mathrm{Me}$ and $2^{\prime} \mathrm{F}$ modifications are stable in mouse plasma and suppress expression of the target gene by several orders of magnitude more efficiently compared to unmodified siRNA (Allerson et al., 2005). Successful use of fully modified siRNA molecules based on alternating $2^{\prime} \mathrm{O}-\mathrm{Me}$ and $2^{\prime} \mathrm{F}$ modifications was demonstrated when studying the properties of singlestranded siRNAs (ssRNAs). ssRNAs with this pattern, with the addition of several PS, 2'O-MOE, and $5^{\prime}(E)$-vinylphosphonate modifications, exhibited biological activity in vitro and in vivo (Lima et al., 2012; Prakash et al., 2015), and modeling of the complex of this siRNA with Ago2 showed that the modifications did not sterically block the interaction of the ssRNA with Ago2 (Schirle et al., 2016).

Despite the fact that duplex cleavage in serum at internal nuclease sensitive sites makes the greatest contribution to siRNA degradation, siRNA cleavage can also occur at other sites. A fully modified siRNA, containing alternating $2^{\prime} \mathrm{O}-\mathrm{Me}$ and $2^{\prime} \mathrm{F}$ modifications, was compared with a partially modified siRNA, containing a combination of $2^{\prime} \mathrm{O}-\mathrm{Me}$ and $2^{\prime} \mathrm{F}$ modifications located along the pyrimidines and the ends of the duplex; both patterns contained PS modifications on the 3 '-overhangs (Hassler et al., 2018) (Figure 3). A cholesterol conjugate of the fully modified siRNA more effectively reduced expression of the Htt gene in HeLa cells compared to a cholesterol conjugate of the partially modified siRNA; the concentrations of siRNA at which expression of the target gene was 50\% suppressed were 70 and $170 \mathrm{nmol} / 1$, respectively (Hassler et al., 2018).

In contrast to serum siRNA cleavage, siRNA degradation in lysosomal hepatocyte extracts occurs mainly by $5^{\prime}$-exonucleases; therefore, siRNA could be further stabilized by PS modifications of the $5^{\prime}$ ends in the $\mathrm{N}$-acetylgalactosamine conjugate to increase the duration and efficiency of its inhibitory effect (Nair et al., 2017). Subcutaneous administration of $10 \mathrm{mg} / \mathrm{kg}$ of conjugate of fully modified at $2^{\prime}$ ribose positions siRNA and $\mathrm{N}$-acetylgalactosamine was shown to cause a $30 \%$ decrease in target gene expression at the protein level for 10 days, while addition of the conjugate with modified $5^{\prime}$ ends reduced the protein level by $80 \%$ for 40 days. Conjugates of fully modified at the $2^{\prime}$ positions and stabilized by PS modifications at both the $3^{\prime}$ and $5^{\prime}$ ends siRNAs with cholesterol and docosahexaenoic acid were examined in vivo (Hassler et al., 2018). The accumulation of conjugates in the liver, kidney, and spleen $24 \mathrm{~h}$ after intravenous and subcutaneous injections was studied. Accumulation of all mentioned above conjugates was two orders of magnitude higher compared to similar conjugates of partially modified siRNA ( $2^{\prime} \mathrm{O}-\mathrm{Me}$ and $2^{\prime} \mathrm{F}$ modifications located on pyrimidines and 


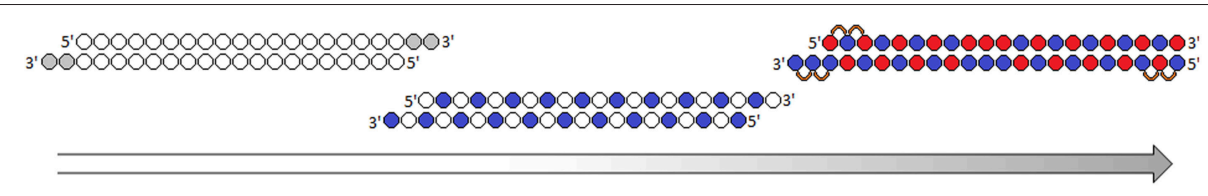

\section{Unmodified siRNA Partially modified siRNA Fully modified siRNA}

FIGURE 3 | Evolution of siRNA chemical modification patterns. Chemical modifications are indicated in gray (deoxyribonucleotides), blue (2'O-Me), red (2'F), and orange (PS) [adapted from Khvorova and Watts (2017)].

duplex ends and PS modifications on $3^{\prime}$-overhangs). However, no control experiment was performed to determine the contribution of the introduction of PS at the $5^{\prime}$ ends to the stability of siRNA conjugates in this study. Since the contribution of $2^{\prime} \mathrm{O}-\mathrm{Me}$ modifications to the nuclease resistance of siRNA is greater than that of 2'F modifications (Cummins et al., 1995; Takahashi et al., 2009), attempts were made to increase the proportion of $2^{\prime} \mathrm{O}$ Me modifications in siRNAs containing 50\% $2^{\prime} \mathrm{O}-\mathrm{Me}$ and $50 \%$ $2^{\prime} \mathrm{F}$ (Khvorova, 2017; Foster et al., 2018). For this purpose, 1,890 different siRNAs were synthesized, aimed at five different genes, varying in sequence ( 15 variants) and pattern of $2^{\prime} \mathrm{O}-\mathrm{Me}$ and $2^{\prime} \mathrm{F}$ modifications (Foster et al., 2018). The optimal introduction of $2^{\prime} \mathrm{O}-\mathrm{Me}$ or $2^{\prime} \mathrm{F}$ modifications for each position in the siRNA was determined via in vitro analysis of primary mouse hepatocytes. Two modification patterns were selected, containing $23 \%$ and $18 \% 2^{\prime} \mathrm{F}$ modifications, the biological activities of which were not less than that of the parent siRNA. Analysis of the biological activities of three different siRNA sequences in vivo showed that a lower content of $2^{\prime} \mathrm{F}$ modifications (18\%) was the most effective. Subcutaneous administration of $1 \mathrm{mg} / \mathrm{kg}$ of the siRNA and Nacetylgalactosamine conjugate to primates showed that the newly selected siRNA ( $18 \% 2^{\prime} \mathrm{F}$ modifications) reduced the protein level by $\sim 70 \%$ for 70 days, while the parent siRNA suppressed the expression of the target gene $A T$ by $\sim 40 \%$ for 40 days. It has been shown that a conjugate of fully modified siRNA (23\% 2'F, 73\% $2^{\prime} \mathrm{O}-\mathrm{Me}$, and one dNMP) and $\mathrm{N}$-acetylgalactosamine suppressed PCSK9 gene expression in the liver of patients following a single subcutaneous injection of $\sim 6 \mathrm{mg} / \mathrm{kg}$ by $\sim 70 \%$ for 6 months (Ray et al., 2017).

When siRNAs are delivered as part of a bioconjugate, they are especially sensitive to the action of nucleases, and the duration of biological action in vivo, and the dose and frequency of drug administration depends on nuclease resistance. Therefore, it is important to pay particular attention to this parameter when creating therapeutic drugs based on siRNA bioconjugates.

\section{BIOCONJUGATES}

The use of bioconjugation as a method of delivering siRNA to cells involves forming siRNA conjugates with (1) biomolecules capable of specifically binding receptors on the cell membrane [folate Thomas et al., 2009, antibodies Song et al., 2005; Dassie et al., 2009; Xia et al., 2009, aptamers Aronin, 2006; McNamara et al., 2006, some peptides Cesarone et al., 2007;

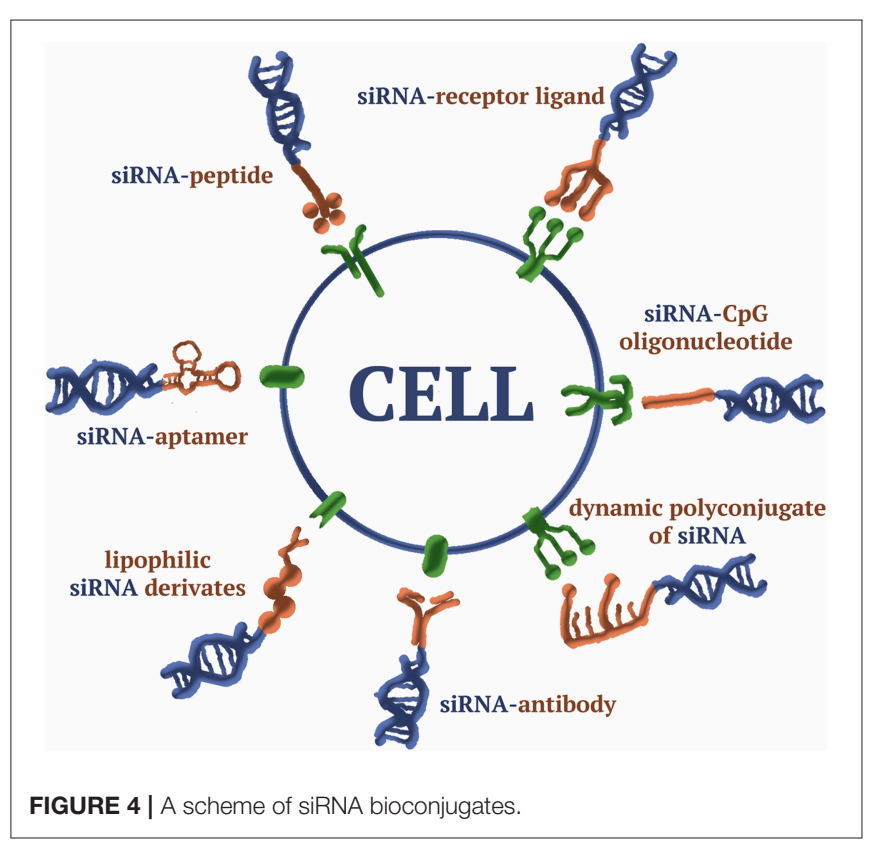

Lau et al., 2012, and carbohydrates Nair et al., 2014], (2) molecules able to penetrate the cell by natural transport mechanisms [cholesterol (Lorenz et al., 2004) and vitamins Nishina et al., 2008], or (3) molecules capable of interacting non-specifically with the cell membrane [positive electrostatic charge and hydrophobicity Kwiatkowska et al., 2013; Meade et al., 2014] (Supplementary Table 1; Figure 4). In addition to the nature of the biogenic molecule, the structure of the linker that binds the siRNA and the biomolecule affects the efficiency of accumulation and the biological activity of the siRNA. In particular, the ability of the linker to be cleaved when the conjugate enters the cells prevents a decrease in the efficiency of RNAi associated with the inhibition of RISC assembly. Disulfide (Turner et al., 2005) and thioether bonds (Meade et al., 2014), pH sensitive bonds [hydrazone (Dovydenko et al., 2016), carboxymethylmaleic anhydride Rozema et al., 2007], or photosensitive bonds ( $\beta$-[bis (4-methoxyphenyl)phenylmethoxy]-2-nitrobenzeneethanol linker Yang et al., 2018) are used as cleavable bonds. Conjugates containing linkers that are stable under the experimental conditions (Lorenz et al., 2004) are widely used, and the structure of the conjugate plays a key role. The most commonly used types of bioconjugates are reviewed below. 


\section{Lipophilic siRNA Derivatives}

Lipids and cholesterol were suggested as the first ligands for conjugation with siRNAs, since they were supposed to ensure the interaction of siRNAs with the cell membrane due to their lipophilic properties and because of endogenous transport mechanisms (Letsinger et al., 1989). Cholesterol is not only part of the membrane, but is also transported into cells by low-density lipoproteins (LDL particles) and high-density lipoproteins (HDL particles) (Brunzell et al., 2008), which bind to corresponding receptors. Absorption of all lipoproteins by cells is carried out through the recognition of protein components of the particles by clathrin-dependent receptor-mediated endocytosis, using LDL and scavenger receptor class B member 1 (SR-BI) receptors that recognize LDL and HDL particles, respectively (Goldstein et al., 1985; Yvan-Charvet et al., 2008).

It has been shown that siRNA and cholesterol derivatives, as well as other lipophilic siRNA derivatives, are able to form complexes with HDL and LDL particles under certain conditions, which, in turn, can bind to the corresponding receptors (Wolfrum et al., 2007). It has also been shown that the hydrophobicity of a lipophilic molecule determines the efficiency of binding a lipophilic conjugate with lipoproteins (Wolfrum et al., 2007). Thus, a cholesterol residue introduced into siRNA provides effective binding to LDL and HDL particles and, as a result, higher activity compared to other lipophilic derivatives. However, the assumption of the penetration of lipophilic siRNA derivatives in the composition of such complexes into cells by receptor-mediated endocytosis has not been confirmed (Wolfrum et al., 2007). The transmembrane protein SIDT1 (Wolfrum et al., 2007) participates in the penetration of complex of lipophilic siRNA derivatives and lipoproteins. SIDT1 facilitates the penetration of dsRNA into cells, by forming channels for diffusion or by facilitating the penetration of dsRNA indirectly via interaction with other proteins (Feinberg and Hunter, 2003; Wolfrum et al., 2007). On the other hand, SIDT1 has a binding domain that interacts with steroid molecules and its localization in the cell depends on the presence or absence of cholesterol in the membrane (Mendez-Acevedo et al., 2017). It has also been shown that the SIDT1 homolog SIDT2 is involved in cellular transport of cholesterol (Mendez-Acevedo et al., 2017) and dsRNA without lipids (Nguyen et al., 2017; Takahashi et al., 2017). However, the specific role of SIDT1 in the penetration of complexes of lipophilic siRNA derivatives with lipoproteins has not been established.

Penetration of siRNA cholesterol conjugates without a carrier was studied in HeLa cells (Gilleron et al., 2015). For this purpose, the expression of genes important for endocytosis (DNM1L, CLTC, CAV1, CDC42, and RAC1) in cells was suppressed, and accumulation of the fluorescently labeled cholesterol conjugate was evaluated. Accumulation of the cholesterol conjugate was reduced by $\sim 40 \%$ compared to accumulation in untreated cells only when expression of DNM1L and CLTC, which participate in clathrin-dependent endocytosis, was inhibited.

In another study (Ly et al., 2017), clathrin-dependent intracellular transport of cholesterol conjugates was investigated by determining the colocalization of fluorescently-labeled endosome proteins and ligands of clathrin-dependent endocytosis with a fluorescently-labeled cholesterol conjugate. In this work, clathrin-dependent endocytosis was shown to account for $25 \%$ of the total intracellular transport of the cholesterol siRNA derivative in the cell. It should be noted that endocytosis is characterized by the ability to sort absorbed endosomal contents for recirculation or degradation (Lakadamyali et al., 2006). Depending on the type of receptor and the content of the endosome, sorting can occur at different stages of endocytosis; sorting and recycling of the LDL receptor takes an average of $\sim 6$ min (Brown and Goldstein, 1976). Analysis of the kinetics of accumulation of cholesterol-modified siRNA revealed that in the first $60 \mathrm{~min}$ after the addition of cholesterol derivatives of siRNA to HeLa cells, only $5 \%$ of the conjugate was recycled, and $20 \%$ of the conjugate was sorted to the degradation pathway (Ly et al., 2017). Thus, it can be assumed that with systemic administration of the cholesterol conjugate, the primary route of transport is interaction with lipoproteins and penetration by receptor-mediated endocytosis into cells expressing the corresponding receptor (LDL or SR-BI receptor). Then, likely at some stage of intracellular transport, lipoproteins and the cholesterol-siRNA conjugate dissociate and the siRNA enters the cytoplasm, where it participates in RNAi. Indeed, many studies have shown that the addition of cholesterol to the $5^{\prime}$ and $3^{\prime}$ ends of the sense strand and the $3^{\prime}$ end of the antisense strand provides manifestation of the biological activity of siRNA upon delivery without a carrier in vitro (Lorenz et al., 2004; Cesarone et al., 2007; Moschos et al., 2007; Alterman et al., 2015; Chernikov et al., 2018) and in vivo (Soutschek et al., 2004; Wolfrum et al., 2007; Byrne et al., 2013; Khan et al., 2016; Haraszti et al., 2017). In most cell lines, the cholesterol-siRNA conjugate shows higher biological activity compared with other conjugates of siRNA and lipophilic derivatives; e.g., lithocholic acid derivatives, saturated fatty acids (C12-C22) (Wolfrum et al., 2007; Prakash et al., 2015), unsaturated fatty acids (Nikan et al., 2016, 2017), or tocopherol (Nishina et al., 2008).

The biodistribution of various lipophilic siRNA conjugates has been extensively studied in a recent paper (Biscans et al., 2018). It was shown that cholesterol conjugates were more effectively retained in the body (62\%) compared with other lipophilic conjugates (27-62\%). Following subcutaneous injection, the cholesterol conjugates accumulated in almost all organs: liver, kidney, adrenal glands, spleen, pancreas, heart, muscle, fat, thymus, lung, injection site, ovaries, and testes. At the same time, cholesterol conjugates accumulated most effectively in the liver, adrenal glands, spleen, and in the skin at the site of administration (Biscans et al., 2018). Cholesterol derivatives accumulated in other organs with the same or lesser efficiency than other lipophilic conjugates; e.g., it was shown that a conjugate of siRNA and saturated fatty acid (docosanoic, C21) accumulated more efficiently than a cholesterol conjugate and inhibited expression of the target gene ( $H t t$ or Ppib) in muscles (20 and $30 \%$ inhibition of $H t t$ and Ppib, respectively) and fat (50\% and $30 \%$ inhibition of $\mathrm{Htt}$ and $\mathrm{Ppib}$, respectively) after subcutaneous injection (20 mg/kg) (Biscans et al., 2018). In this study, it was shown that the main factor determining the nature of the biodistribution of conjugates is their lipophilicity. Conjugates of siRNA with lower lipophilicity; i.e., derivatives 
of retinoic acid, lithocholic acid, and docosahexanoic acid with greater efficiency than cholesterol conjugates accumulated in the kidneys, bladder, and lungs of the mouse after subcutaneous injection (Biscans et al., 2018). This fact is consistent with previous data that showed that more lipophilic conjugates bind more efficiently to serum components, and thus are not excreted by the kidneys (Wolfrum et al., 2007; Osborn et al., 2018).

Lipophilic derivatives after subcutaneous or intravenous injection do not penetrate the blood-brain barrier (BBB) (Biscans et al., 2018). Therefore, attempts were made to directly inject derivatives into the brain of the mouse to suppress gene expression in the brain (Alterman et al., 2015; Nikan et al., 2016, 2017). Since docosahexaenoic acid is the most common polyunsaturated fatty acid in the mammalian brain, conjugation of siRNA with docosahexaenoic acid more effectively suppressed the expression of the target gene (Nikan et al., 2016) than other lipophilic conjugates (Alterman et al., 2015). Injection of the siRNA-docosahexaenoic acid conjugate into the brain striatum of the mouse $(\sim 1.25 \mathrm{mg} / \mathrm{kg})$ caused a decrease in the mRNA level of the target gene $(\mathrm{Htt})$ not only in the striatum $(73 \%)$ but also in the cortex (52\%) of the corresponding hemisphere (Nikan et al., 2016). However, no decrease in Htt mRNA was observed in the striatum and the cortex of the opposite hemisphere. An assessment of the toxicity of the conjugate in the brains of animals, at a dose 20 times higher than that in a study of biological activity, showed that this conjugate does not elicit an immune response or neuronal death. The therapeutic significance of suppressing the expression of the $\mathrm{Htt}$ gene was shown in another study in a mouse model of Huntington's disease using ASO (Kordasiewicz et al., 2012). It was shown that suppression of the expression of both alleles (mutant and wild-type) resulted in restoration of a healthy animal phenotype. Therefore, the use of docosahexaenoic acid for conjugation with siRNA may be a promising approach for the treatment of various hereditary neurodegenerative diseases, including Huntington's disease. Thus, such conjugates can be considered as a universal platform for siRNA delivery throughout the body since lipophilic siRNA derivatives can accumulate and exhibit biological activity in a variety of tissues and organs.

\section{siRNA and Peptide Conjugates}

Some proteins and peptides are able to penetrate into the cell due to endogenous transport mechanisms, as well-transfer other molecules into the cell. The main mechanisms of peptide transport include binding to surface proteins, glycoconjugates [targeted peptides Pooga et al., 1998; Alberici et al., 2013], or anionic cell lipids, followed by absorption by endocytosis, membrane penetration (cell penetrating peptides [CPPs] Vives et al., 1997; Thoren et al., 2000; Console et al., 2003; Heitz et al., 2009; van den Berg and Dowdy, 2011; Lee et al., 2013; Gagat et al., 2017), membrane lysing, or pore formation in the membrane [lytic peptides (Meyer et al., 2009)]. There are two main ways of obtaining such peptides: using phage display, or using parts of proteins that perform similar functions in nature. In this section, the main approaches for siRNA delivery by peptide are reviews.

The ability of peptides to specifically interact with certain proteins on the cell surface due to specific elements in their tertiary structure was used for targeted delivery of siRNAs. Different targeted peptides were conjugated to siRNAs and such conjugates possessed biological activity in vitro (Cesarone et al., 2007; Alam et al., 2011; Alberici et al., 2013) and in vivo (Liu et al., 2014). For example, a conjugate of siRNA and the peptide "CSKC," which mimics insulin-like growth factor 1 (IGF-1), effectively penetrated MCF7 cells expressing the IGF-1-specific receptor and suppressed expression of the IRS1 target gene by $60 \%$ without the help of transfection agents (Cesarone et al., 2007).

One of the most successful examples of targeted peptides is the cyclic RGD (cRGD) peptide. cRGD is part of the iRGD peptide obtained by selecting a phage library of cyclic peptides for binding to a xenograft PC-3 tumor (Sugahara et al., 2009). cRGD binds to $\alpha \mathrm{V} \beta 3 / 5$ integrins that are expressed at a high level in tumor cells and vascular endothelium cells (Dubey et al., 2004; Weis and Cheresh, 2011). Conjugation of this peptide with siRNA contributed to the accumulation and manifestation of the biological activity of siRNA in tumor cells in culture (Alam et al., 2011) and in vivo following six intravenous injections in animals with xenograft A549 tumors (reduction of VEGFR2 gene mRNA by $55 \%$ ), which was accompanied by a decrease in tumor growth (Liu et al., 2014) (Supplementary Table 1). Attempts to increase the number of RGD peptides in the siRNA conjugate were made; however, the introduction of additional molecules of this peptide did not have a direct dose-dependent effect on biological activity. Assessment of biological activity to suppress expression of the GFP gene in $\mathrm{M}^{2} 1^{+} \mathrm{GL}_{3}$ cells showed that a siRNA conjugate with two cRGD peptides has negligible activity (20\%), a conjugate with four cRGD peptides showed moderate biological activity (37\%), and a conjugate with three cRGD peptides had the highest biological activity (73\%) (Alam et al., 2011).

Covalent attachment of peptides can not only increase the efficiency of siRNA accumulation in cells, but also ensure the specificity of their actions in target cells. A peptide with the "LEVDG" sequence attached to siRNA blocks RISC (Koehn et al., 2010) assembly; however, this sequence is specifically recognized and cleaved by caspase- 4 , which is expressed in Jeg-3 choriocarcinoma cells. Thus, following the introduction of antiSTAT3 siRNA conjugated with the "LEVDG" peptide into Jeg-3 cells, effective (up to 70\%) suppression of target gene expression was observed (Supplementary Table 1), whereas in the control HEK293 cells not expressing caspase-4, suppression of the STAT3 gene was not observed (Koehn et al., 2010).

Due to the presence of positively charged amino acids in its composition and the secondary structure, CPP peptides, such as penetratin (Moschos et al., 2007), transportan (Muratovska and Eccles, 2004) and trans activator of transcription (Tat) (van den Berg and Dowdy, 2011) are able to penetrate the cell membrane, as well as deliver covalently attached nucleic acids into cells (Chiu et al., 2004; Muratovska and Eccles, 2004). It has been shown in a number of studies (Muratovska and Eccles, 2004; Cesarone et al., 2007) that CPP-siRNA conjugates exhibit biological activity when added to cells. However, the use of such conjugates in vivo is limited because they are toxic and can elicit an immune response (Boeckle et al., 2005; El-Andaloussi et al., 2007; Moschos et al., 2007). 
Another limitation to the use of CPPs as siRNA delivery agents is the formation of complexes of positively charged CPP with siRNA, which prevents the siRNA from interacting with RISC components. To avoid this, neutralizing or shielding the negative charge of the siRNA by introducing chemical modifications [tertbutyl-S-acyl-2-thioethyl phosphotriester ( $t$ Bu-SATE) (Table 1, 2)] has been proposed (Meade et al., 2014; Hamil and Dowdy, 2016). The introduction of $t \mathrm{Bu}$-SATE modifications into the siRNA conjugate made it possible to obtain siRNA conjugates with several cationic peptides without inhibiting RNAi. At the same time, the biological activity of such conjugates directly depended on the number of CPP molecules of the Tat peptide present (Meade et al., 2014). Conjugates containing four Tat peptides more effectively suppressed the expression of a target gene in cells compared with a conjugate with two or three Tat peptides. However, despite promising in vitro results (Meade et al., 2014; Kolosenko et al., 2017), this siRNA conjugate has not yet been studied in vivo.

Another successful example of the use of CPP as a ligand for conjugation with siRNA is the skin penetrating and cell entering (SPACE) peptide, obtained by the phage display method by selecting peptides that penetrate the epidermis (Hsu and Mitragotri, 2011). Attachment of the SPACE peptide to siRNA promoted penetration of the siRNA through the epidermis and dermis following application on the skin surface. A single application of $\sim 12 \mathrm{mg} / \mathrm{kg}$ of the siRNA conjugate with the SPACE peptide suppressed the expression of IL10 and GAPDH in the epidermis by 28 and 47\%, respectively. The inclusion of such a conjugate in the composition of lipoplexes enriched with the SPACE peptide results in a more effective downregulation of the expression of the target gene $(G A P D H)$.

To solve the problem of effective in vivo accumulation of siRNA, an interesting approach using siRNA containing a chemical modification at the $3^{\prime}$ end of the sense strand capable of forming a covalent bond between siRNA and albumin following intravenous injection of siRNA was proposed (Lau et al., 2012). For this purpose, succinimidyl 4-[N-maleimidomethyl] cyclohexane-1-carboxylic acid was attached to siRNA using the amino group at the $3^{\prime}$ end of the sense strand; the resulting molecule ("activated siRNA") could interact with albumin to form a disulfide bond. When BALB/c mice were injected with the "activated siRNA" capable of binding albumin, there was a more efficient accumulation of siRNA in the myocardium compared to unmodified siRNA, as well as a decrease in the mRNA level of the IGF-IR target gene by 35\% (Supplementary Table 1). However, the toxic effect of the "activated siRNA" has not yet been investigated.

Another approach for the delivery of siRNA to target cells uses its conjugation with lytic peptides, which facilitate the release of siRNA from the endosome (Varkouhi et al., 2011). The main mechanisms that increase the efficiency of the release of siRNA from the endosome are (1) formation of transmembrane pores by peptides due to their amphiphilicity and ability to form complexes [melitin, cytolytic peptide from bee venom (Meyer et al., 2009), ricin, and ribosome-inactivating protein from the oil (Sun et al., 2004)]; (2) protonation of the main groups of peptides with a decrease in the $\mathrm{pH}$ of the endosome, followed by an increase in the osmotic pressure inside and rupture of its membrane [polyhistidine (Chen et al., 2017)]; or (3) local membrane destabilization due to the fusogenic properties of proteins and membrane penetration of the endosome [glycoprotein $\mathrm{H}$ from the herpes virus ( $\mathrm{Tu}$ and $\mathrm{Kim}, 2008$ ), hemagglutinin-2 domain of the influenza virus (Wadia et al., 2004; Lee et al., 2011), and diphtheria toxin domain (Barati et al., 2002)]. Despite the efficiency of the action of lytic peptides, the primary issue is toxicity, since the formation of pores and increased osmotic pressure inside the endosome implies its destruction. In this case, the approach in which the membrane is locally destabilized is less toxic, since it does not lead to significant damage to the endosome and therefore is the most promising. However, to date, an effective and non-toxic endosomolytic agent based on peptides has not been developed.

The use of siRNA and peptide conjugates for siRNA delivery is a promising approach; however, at present, the efficiency and specificity of delivery provided by peptides does not reach the level at which they do not exhibit toxic and immunogenic effects.

\section{siRNA and Receptor Ligand Conjugates}

The main factors affecting the efficiency of specific delivery to target cells are the efficiency of ligand binding to the receptor and the degree of expression of the receptor on the membrane surface. Typically, the interaction of the ligand with the receptor is characterized by high specificity, so introduction of these molecules contributes to effective targeted delivery when covalently attached to molecules (Nikam and Gore, 2018). The most successful example of this strategy is the use of $\mathrm{N}$-acetylgalactosamine as a ligand for siRNA delivery because its interaction with the asialoglycoprotein receptor (ASGPR) occurs with high efficiency $\left(\mathrm{K}_{\mathrm{d}}=2.5 \mathrm{nM}\right)$ and this receptor is expressed at a high level in hepatocytes $\left(0.5-1 \times 10^{6}\right.$ molecules per cell) (Spiess, 1990). Conjugation of siRNA with $\mathrm{N}$-acetylgalactosamine contributes to efficient delivery of siRNA and the conjugate suppresses expression of the target gene (PCSK9) by $70 \%$ following a single subcutaneous injection of $\sim 6$ $\mathrm{mg} / \mathrm{kg}$ (Ray et al., 2017) (Supplementary Table 1). The level of ASGPR in hepatocytes is so high that reducing its expression by $50 \%$ does not reduce the biological activity of the siRNA and $\mathrm{N}$-acetylgalactosamine conjugate; only suppression by $95 \%$ blocks the action of this conjugate (Willoughby et al., 2018). For these reasons, and due to inexpensive synthesis, siRNA and Nacetylgalactosamine conjugates are among the most promising prototypic drugs for introduction in the clinic for the treatment of liver diseases.

Conjugation with folic acid was proposed for specific accumulation of siRNA in tumor cells (Thomas et al., 2009). Folic acid is a precursor of tetrahydrofolate, which is essential for the synthesis of nucleotides de novo, and thus is essential for dividing cells. Folic acid penetration into cells occurs via receptor-mediated endocytosis, via the glycoprotein folic acid receptor, which binds strongly to folate $\left(\mathrm{K}_{\mathrm{d}}=10^{-10} \mathrm{M}\right)$. It has been shown that expression of folic acid receptor in tumor cells of different origin is significantly higher compared with the expression level in normal cells (Parker et al., 2005; Xia and Low, 2010). Presumably, the penetration of folate-containing siRNAs also occurs via receptor-mediated endocytosis (Low et al., 2008); therefore, the penetration efficiency of folate-containing 
siRNAs into tumor cells is significantly higher compared with the efficiency of conjugate penetration into normal cells. In vivo, fluorescently-labeled siRNA and folate conjugates were shown to accumulate more efficiently in a mouse tumor compared to unmodified siRNA (Thomas et al., 2009). However, the use of siRNA and folate conjugates is limited to experimental purposes due to sophisticated synthesis.

\section{siRNA and Aptamer Conjugates}

Aptamers are synthetic oligoribonucleotides (molecular weight, $\sim 6-30 \mathrm{kDa}$ ) with a complex tertiary structure, which allows specific binding to molecules (Zhou and Rossi, 2017). It has been shown that the attachment of aptamers to siRNAs contributes to specific accumulation in certain cell types (Catuogno et al., 2018). For instance, siRNA conjugation with the A10 aptamer specific to prostate specific membrane antigen (PSMA) promoted effective delivery of siRNA to prostate tumor cells, and the biological activity of the conjugate was comparable to that observed in the case of siRNA delivered by lipoplexes (McNamara et al., 2006). The conjugate silenced PKL1 and Bcl2 genes with 85 and $90 \%$ efficiency, respectively, in the xenographic prostate LNCaP tumor-bearing mice model after 10 intratumoral injections; a decrease in tumor growth and regression were also observed (McNamara et al., 2006) (Supplementary Table 1). In the same xenograft tumor model, another shRNA (short hairpin RNA) and aptamer A10-3 to PSMA conjugate also exhibited biological activity (65\% inhibition of the PRKDC gene), but tumor regression occurred after two intratumoral injections only in combination with ionizing radiation (Ni et al., 2011) (Supplementary Table 1).

A conjugate of siRNA and the A-1 aptamer specific for the gp120 surface protein of human immunodeficiency virus 1 (HIV1) capsid was synthesized as an anti-HIV-1 drug (Neff et al., 2011). In humanized Rag2 ${ }^{-/-} \gamma \mathrm{c}^{-/-}$(RAG-hu) mice 3 weeks after infection with HIV-1, weekly administration $(0.38 \mathrm{mg} / \mathrm{kg}$, intravenous) of this conjugate reduced the concentration of viral RNA in the plasma of animals by 105 times. However, a few weeks after treatment, the amount of viral RNA in the plasma was restored almost to the initial level (Supplementary Table 1).

Another interesting property of some aptamers is their ability to penetrate the BBB. For instance, it has been shown that the aptamers Gint4.T and GL21.T, specific to beta-type plateletderived growth factor receptor $(\operatorname{PDGFR} \beta)$, can penetrate the in vitro model of the BBB (Esposito et al., 2016). This siRNA conjugate is able to accumulate in xenograft glioblastomas after several intravenous injections, suppress expression of the target gene (STAT3) by $60 \%$, and reduce the rate of tumor growth (Esposito et al., 2018).

In addition to RNA aptamers, DNA aptamers have also been used for the delivery of siRNAs (Lai et al., 2014). The G-quadruplex-forming G-rich deoxyoligonucleotide AS1411 specifically binds nucleolin, an oncogene protein expressed at a high level in many cancer cell types (Ireson and Kelland, 2006). The AS1411-based DNA aptamer aptNCL conjugated with siRNA enables its delivery and biological activity in lung cancer cells in vitro and in vivo (Lai et al., 2014).
Although siRNA and aptamer conjugates have high biological efficiency at the experimental level, their use in the clinic has been limited by such factors as nuclease cleavage, filtration by the kidneys, polyanion effects, and the immune response. Selection of a new specific sequence of an aptamer to a specific object (systematic evolution of ligands by exponential enrichment [SELEX]) is fast, but the resulting aptamers do not always have high specificity for the target antigen (Yan and Levy, 2018). Nevertheless, in most cases, conjugation of siRNA with aptamers provides reproducible specific delivery of siRNA to target cells, and the possibility of obtaining aptamers directed to any protein on the surface of the cell membrane suggests this may be a promising approach. Therefore, the use of a modified SELEX protocol to search for chemically modified aptamers and conjugation with fully modified siRNAs can increase the effectiveness and duration of the therapeutic effect of aptamerbased conjugates of siRNA and their introduction into clinical practice (Hori et al., 2018).

\section{Antibody-siRNA Conjugates}

Antibody-siRNA conjugates (ARCs) have been successfully used for targeted delivery of siRNA to specific types of cells expressing receptor-antigens; however, the effectiveness of ARCs varies significantly. For example, it has been shown that an ARC with an antibody against the insulin receptor suppresses expression of the target gene by $90 \%$ in HEK 293 cells at a concentration of $115 \mathrm{nM}$ (Supplementary Table 1) (Xia et al., 2009). Another ARC with an antibody to the Lewis-Y protein inhibited the expression of the target gene by $60 \%$ at a concentration of $300 \mathrm{nM}$ only when the cells were treated with chloroquine, an agent that inhibits endosome maturation (Supplementary Table 1) (Ma et al., 2011). However, the non-covalent siRNA complex with the same antibody, formed by electrostatic interaction of oligoarginine and siRNA, showed $60 \%$ biological activity (300 nM) in the absence of chloroquine. It is likely that the efficiency of endosomal escape mediated by chloroquine or oligo-arginine is an important factor for the biological activity of ARCs. The biological activity of both covalent and non-covalent siRNA complexes and antibodies has been shown in vivo in a number of studies (Song et al., 2005; Xia et al., 2007; Baumer et al., 2015; Sugo et al., 2016; Ibtehaj and Huda, 2017). However, a systemic comparison of the effectiveness of the biological activity of ARCs differing in target antigens was carried out only in one study (Cuellar et al., 2014), which showed that along with the level of expression of the receptor-antigen, the type of intracellular transport of the receptor influences the interfering activity of the ARC. However, no direct correlation was found between the type of penetration of the antibody complex with the receptorantigen and the biological activity of the ARC. Such a factor as the presence of a cleavable bond between the siRNA and antibody did not affect the interfering activity of the ARC. Since in this study (Cuellar et al., 2014), the efficiency of the binding of antibodies to the corresponding receptors was not compared, it is not possible to evaluate the efficiency of their dissociation and the degree of endosomal escape of the conjugates. However, it is likely that this is a significant factor in determining the biological activity of ARCs. 
The mechanism of penetration into cells of an ARC with the TENB2 antibody exhibiting high biological activity was studied (Cuellar et al., 2014). It was shown that the silencing of genes associated with clathrin-dependent receptor-mediated endocytosis led to a decrease in the efficiency of gene silencing by ARC. However, the suppression of the expression of RAB5C and HPS4, which are associated with intracellular transport, increased the silencing activity of the ARC. The product of the RAB5C gene likely sorts endosomal contents to the recycling pathway (Chen et al., 2014), while the product of the HPS4 gene is involved in regulation of RNAi (Lee et al., 2009). It has been shown that the product of the HPS4 gene reduces the amount of RLC and RISC proteins in the cell by increasing the frequency of lysosomes merging with multivesicular bodies, where, presumably, RNAi proteins are located (Lee et al., 2009). Thus, the suppression of HPS4 gene expression leads to an increase in the efficiency of RNAi in cells and a corresponding increase in the activity of the conjugate. The effectiveness of PPID gene silencing by the ARC with the TENB2 antibody after three intravenous injections of $24 \mathrm{mg} / \mathrm{kg}$ in xenograft PC3-TENB2-high tumorbearing nude mice was only 33\% (Supplementary Table 1) (Cuellar et al., 2014).

In another study (Sugo et al., 2016), an $\mathrm{F}_{\mathrm{ab}}$ antibody fragment, an immunoglobulin molecule segment that binds an antigen that has lower affinity for the target receptor than antibody, was used for conjugation with siRNA. After 4 weekly intramuscular injections $(\sim 3.6 \mathrm{mg} / \mathrm{kg})$ of the conjugate of siRNA and $\mathrm{F}_{\mathrm{ab}}$ fragment to the transferrin receptor, the MSTN mRNA level was decreased by $72 \%$, which increased the average running distance of mice by $24 \%$ in the peripheral arterial disease model (Sugo et al., 2016). Intramuscular injection of only $\sim 0.05 \mathrm{mg} / \mathrm{kg}$ of the conjugate of siRNA and $\mathrm{F}_{\mathrm{ab}}$ fragment to the transferrin receptor resulted in suppression of the HPRT target gene at the injection site by $55 \%$. High biological activity of the siRNA and $\mathrm{F}_{\mathrm{ab}}$ fragment conjugate in muscle cells following intravenous injection was demonstrated by Avidity Bioscience. The mRNA level of the target MSTN gene was decreased by $90 \%$ and lasted for 20 days following a single intravenous injection of this conjugate, while the antigen for the $\mathrm{F}_{\mathrm{ab}}$ fragment was also a transferrin receptor. $\mathrm{F}_{\mathrm{ab}}$ fragments more efficiently than antibodies escape endosomes into the cytoplasmic space after being absorbed by cells. This is likely due to lower receptor binding efficiency and low molecular weight $(55 \mathrm{kDa})$. Therefore, this approach is promising for the targeted delivery of siRNA to cells; however, a direct comparison of ARCs with conjugates of siRNA and $\mathrm{F}_{\mathrm{ab}}$ fragments has not yet been carried out.

Conjugation of siRNAs with antibodies to deliver siRNA to target cells has several advantages compared with the conjugation of siRNAs with other molecules, such as high ligand binding efficiency $\left(\mathrm{K}_{\mathrm{d}}<10^{-9-10}\right)$ and prolonged presence in blood due to high molecular weight $(\sim 150 \mathrm{kDa})$. However, the immune response and low efficiency of the endosomal yield are the main disadvantage of this approach. Thus, further optimization, including the use of humanized antibodies or $\mathrm{F}_{\mathrm{ab}}$ fragments, endosomolytic agents, and fully modified siRNAs, is required for effective use of ARCs in the clinic.

\section{siRNA and CpG Oligonucleotide Conjugates}

As an alternative method of siRNA delivery to target cells, systems that provide an efficient release of siRNA from endosomes to the cytoplasm are used. For example, conjugation of DsiRNA with CpG-containing oligodeoxyribonucleotides leads to recovery of the interfering activity of DsiRNA in cells expressing the TLR9 receptor due to endosomal release mediated by TLR9 (Nechaev et al., 2013). Thus, the conjugate is biologically active only in cells expressing the TLR9 receptor, such as cells of the immune system: B-lymphocytes, dendritic cells, and macrophages, as well as in some types of cancer (Zhang et al., 2013). The therapeutic effect of the siRNA and CpG oligonucleotide conjugate has been shown in various tumorbearing mouse models following systemic administration of the conjugate over several weeks (Kortylewski et al., 2009; Zhang et al., 2013; Hossain et al., 2014). However, since the injection of $\mathrm{CpG}$ oligonucleotides leads to the activation of cytokines and interleukins, their use is limited. Also, its application in vivo is limited to local injections due to rapid degradation in serum. Introduction of chemical modifications to such DsiRNA conjugates to increase nuclease resistance will likely change the interaction of the conjugate with Dicer (Nechaev et al., 2013).

Further, to suppress the expression of the target gene (STAT3), researchers conjugated the $\mathrm{CpG}$ oligonucleotide with the DNA duplex, which is part of the promoter of the STAT3 gene, so that when it enters the nucleus of the target cell, this duplex binds to the corresponding transcription factor and blocks its transcription (Sen et al., 2012). This conjugate showed a therapeutic effect in a mouse model of acute myeloid leukemia after several intravenous injections ( $5 \mathrm{mg} / \mathrm{kg}$ ) (Zhang et al., 2016). The first stage of clinical trials of this conjugate for the treatment of B-cell non-Hodgkin's lymphoma is planned for 2019.

\section{Dynamic Polyconjugates}

Dynamic polyconjugates, which contain two types of cleavable bonds, were developed by Arrowhead Pharmaceuticals to facilitate the endosomal escape of siRNA (Rozema et al., 2007). A polyconjugate is an amphiphilic polymer consisting of poly(butyl-aminovinyl ether) (PBAVE), to which polyethylene glycol residues and a targeted ligand molecule ( $\mathrm{N}$-acetylgalactosamine) are attached using an acid-cleavable carboxy dimaleimide anhydride linker. siRNA molecules are connected to PBAVE through linkers containing disulfide bonds that can be cleaved in the cytoplasm of the cell. Thus, following penetration of the dynamic polyconjugate by receptor-mediated endocytosis into the cell and entry into the acidic environment of the endosome, the carboxy-diimide anhydrite bonds are cleaved and $\mathrm{N}$-acetylgalactosamine and polyethylene glycol dissociate from the polyconjugate. Following this, the newly formed amino groups on PBAVE are protonated, which leads to a decrease in endosomal $\mathrm{pH}$, an increase in osmotic pressure, and rupture of the endosomal membrane. Conjugates of PBAVE and siRNA are released into the cytoplasm, followed by cleavage of the disulfide bond and detachment of the siRNA from the polymer (Rozema et al., 2007). Due to 
effective endosomal escape, dynamic polyconjugates exhibit high biological activity: suppression of the target gene F7 was observed in cynomolgus monkeys with $99 \%$ efficiency for 80 days following a single intravenous injection (5 $\mathrm{mg} / \mathrm{kg}$ ) (Rozema et al., 2015). Another drug based on a dynamic polyconjugate is the PBAVE polymer, conjugated with polyethylene glycol or $\mathrm{N}$-acetylgalactosamine residues (NAGPBAVE), but without covalent attachment of siRNA (Wong et al., 2012). In this case, NAG-PBAVE is injected with cholesterolmodified siRNA. Intravenous injection of the cholesterol-siRNA conjugate results in accumulation of siRNA mainly in the liver; the NAG-PBAVE component also accumulates in this organ. This co-administration increases the biological activity of the cholesterol-siRNA substantially: 75\% suppression of the target gene $(A p o B)$ in the livers of rhesus monkeys was observed over 30 days following one intravenous injection of the drug (2 mg/kg siRNA and $15 \mathrm{mg} / \mathrm{kg}$ NAG-PBAVE) (Wong et al., 2012).

Another drug developed by Arrowhead Pharmaceuticals represents a conjugate of siRNA and cholesterol administered together with a conjugate of $\mathrm{N}$-acetylgalactosamine and melitinlike peptide (NAG-MLP) (Wooddell et al., 2013). Melitin-like protein is an endosomolytic pore-forming peptide capable of increasing the efficiency of the release of the cholesterol conjugate from endosomes and, therefore, its biological activity. It has been shown that after single intravenous injection of the cholesterolsiRNA conjugate $(1 \mathrm{mg} / \mathrm{kg})$ together with NAG-MLP $(6 \mathrm{mg} / \mathrm{kg})$, expression of the $F 7$ target gene in the mouse liver was suppressed with $99 \%$ efficiency, while the cholesterol-siRNA conjugate (10 $\mathrm{mg} / \mathrm{kg}$ ) alone, without NAG-MLP, reduced expression of the F7 gene only by $20 \%$ (Wooddell et al., 2013). This co-administration system was used to treat chronic hepatitis B virus in patients in clinical trials. A $90 \%$ decrease of hepatitis B surface antigen (HBsAg) was observed for 50 days after a single injection of 4 $\mathrm{mg} / \mathrm{kg}$ of a mixture of two cholesterol-siRNA conjugates (anti$H B x$ and anti-preC-C) and NAG-MLP.

However, clinical trials of several drugs based on PBAVE and melitin for the treatment of liver diseases were halted due to high toxicity demonstrated in a non-human primate study (Turner et al., 2018). The company switched to TRiM technology based on the conjugation of siRNA and N-acetylgalactosamine; however, the specific structure of the drug has not yet been disclosed (Wooddell et al., 2017) (see section "siRNA and receptor ligand conjugates").

\section{SIRNA CONJUGATES IN THE CLINIC}

Onpattro (Patisiran), the first commercially available siRNAbased drug, was released for the treatment of hereditary transthyretin polyneuropathy in August 2018 by Alnylam Pharmaceuticals (Adams et al., 2018; Garber, 2018; Solomon et al., 2019). Onpattro is an anti-TTR siRNA containing several $2^{\prime} \mathrm{O}-\mathrm{Me}$ modifications in complex with a cationic lipid, phospholipid, cholesterol, and a conjugate of polyethylene glycol and lipid. Its administration every 3 weeks for 18 months contributes to a significant reduction in the symptoms of the disease compared with patients taking placebo. However, the fact that its use has to be combined with corticosteroids, acetaminophen, and antihistamines is evidence of the proinflammatory effect of the lipids used in Onpattro. Moreover, the side effects of this drug include redness, nausea, headache, pain in the back and abdomen, and breathing difficulties. Due to these reasons, subsequent drugs developed by Alnylam Pharmaceuticals do not use lipids for delivery and are presented as conjugates of siRNA and $\mathrm{N}$-acetylgalactosamine. Currently, six drugs based on this platform are at the most advanced steps of development in Alnylam pipline; three are in the third stage, and three are in the second and first stages of clinical trials (Huang, 2017). Moreover, these conjugates all have the same structure and chemical modifications ( $2^{\prime} \mathrm{O}-\mathrm{Me}, 2^{\prime} \mathrm{F}$, and PS) and differ only in siRNA sequences and chemical modification patterns.

Advanced products under development by other companies (Dicerna Pharmaceuticals, Arrowhead Pharmaceuticals, and Silence Therapeutics) that suppress gene expression in hepatocytes are based on covalent conjugates of siRNA and $\mathrm{N}$-acetylgalactosamine (Crooke et al., 2018; Nikam and Gore, 2018; Springer and Dowdy, 2018). Thus, significant success was achieved in the delivery of siRNA to liver cells; the search for new targets for siRNA and the determination of the dose required for a therapeutic effect will expand the range of drugs aimed at the liver (Zatsepin et al., 2016; Shen and Corey, 2017). The design of systems for delivery to organs is a fast developing area, however, currently such drugs are only at the preclinical stage (Benizri et al., 2019), successful delivery to such organs as the kidneys may be the next step (Khvorova and Watts, 2017).

\section{CHALLENGES AND LIMITATIONS OF USING SIRNA BIOCONJUGATES IN CLINICS}

The use of chemical modifications in siRNA conjugates significantly improved their bioperformance allowed to solve such problems as: some of non-target effects-the cellular immune response is reduced by the presence of $2^{\prime} \mathrm{O}-\mathrm{Me}$ siRNA modifications (Judge et al., 2006); the probability of RISC* binding to non-target mRNA molecules can be reduced by decreasing the melting temperature of the seed region of the siRNA by introducing UNA or GNA modifications (Janas et al., 2017); the use of a fully modified siRNA molecules increases the time of inhibition of the target gene up to half of the year (Ray et al., 2017). Bioconjugation strategies described above can improve the ability of conjugates to accumulate in certain organs and penetrate certain types of target cells without the help of transfection agents or other means of delivery have been developed. However, there are still a number of unsolved problems that limit the possibility of transfer of drugs from the laboratory bench to the clinic. The main problem of this kind is the low bioavailability of siRNA conjugates and unfavorable pharmacokinetics, which, together with the rather high cost of obtaining such drugs in quantities necessary to achieve a therapeutic effect, impedes their use in the clinic. The low bioavailability of siRNA conjugates is primarily due to the fact that in order for siRNA to enter the cytoplasm of a target cell after systemic administration, it has to overcome numerous barriers-the endothelial barrier when leaving the 
bloodstream to the tissue, as well as to escape siRNA from the endosome to the cytoplasm. The overcoming of these barriers is complicated by the unfavorable pharmacokinetics of such drugs, associated with their relatively low molecular weight, which lies below the filtration limit, due to which the drugs are rapidly removed from the bloodstream by renal filtration. In this regard, the development of alternative routes of administration, such as subcutaneous or local in which there is a deposit and the gradual release of the drug is promising, as well as approaches aimed at increasing the duration of the circulation of the drug in the bloodstream (Nair et al., 2017). Another option-the targeted delivery, which can be implemented only for some organs and tissues with sufficient efficiency, moreover, using the advantage of specific binding to target cells does not cancel the dependence of this process on the concentration of drug in the blood or interstitial fluid and the duration of maintenance of an effective concentration. The necessity to administer high doses of drugs to achieve a therapeutic effect raises the problem of specificity and possible side effects, the severity of which increases at high concentrations. It can be expected, that along with non-specific effects associated with the suppression of partially homologous targets, which can be eliminated by sequence selection and conjugate design, immunostimulation, the metabolic effects of unnatural analogs, including cumulative and long-term ones, as well as the intervention of exogenous siRNA into cellular regulatory systems of miRNA in competition for RISC, can become the main non-specific effects important for the safety of clinical use. In this regard, the main challengers of biomedical research are increasing the bioavailability, biological activity and targeting of delivery, which will reduce the therapeutic doses of drugs based on siRNA conjugates.

\section{CONCLUSIONS}

The introduction of molecules of natural origin into the composition of siRNA is a promising approach for nonviral delivery and has clear advantages over other approaches

\section{REFERENCES}

Adams, D., Gonzalez-Duarte, A., O’Riordan, W. D., Yang, C. C., Ueda, M., Kristen, A. V., et al. (2018). Patisiran, an RNAi therapeutic, for hereditary transthyretin amyloidosis. N. Engl. J. Med. 379, 11-21. doi: 10.1056/NEJMoa1716153

Addepalli, H., Meena, P.eng, C. G., Wang, G., Fan, Y., Charisse, K., et al. (2010). Modulation of thermal stability can enhance the potency of siRNA. Nucleic Acids Res. 38, 7320-7331. doi: 10.1093/nar/gkq568

Akinc, A., Zumbuehl, A., Goldberg, M., Leshchiner, E. S., Busini, V., Hossain, N., et al. (2008). A combinatorial library of lipid-like materials for delivery of RNAi therapeutics. Nat. Biotechnol. 26, 561-569. doi: 10.1038/nbt1402

Alam, M. R., Ming, X., Fisher, M., Lackey, J. G., Rajeev, K. G., Manoharan, M., et al. (2011). Multivalent cyclic RGD conjugates for targeted delivery of small interfering RNA. Bioconjug. Chem. 22, 1673-1681. doi: 10.1021/bc200235q

Alberici, L., Roth, L., Sugahara, K. N., Agemy, L., Kotamraju, V. R., Teesalu, T., et al. (2013). De novo design of a tumor-penetrating peptide. Cancer Res. 73, 804-812. doi: 10.1158/0008-5472.CAN-12-1668

Allerson, C. R., Sioufi, N., Jarres, R., Prakash, T. P., Naik, N., Berdeja, A., et al. (2005). Fully $2^{\prime}$-modified oligonucleotide duplexes with improved in vitro (physical methods, delivery using cationic lipids, and polymers): specificity of penetration into target cells and absence of toxic effects (Lee et al., 2016; Benizri et al., 2019). The primary difficulty in designing bioconjugates is the necessity of selecting specific ligands for individual applications due to the specificity of ligand-receptor interactions. From this point of view, the use of lipophilic siRNA conjugates is less specific, since LDL receptors are expressed at a high level by various cell types; however, it could be beneficial if high selectivity of delivery to certain cell types is not required and accumulation of the drug into non-target cells does not cause undesirable effects (Turanov et al., 2018). The latest patterns of chemical modifications can reduce the $\mathrm{ID}_{50}$ and increase the duration of the biological effect of siRNA conjugates. As a result, the application of siRNAbased drugs in clinical practice in the next few years may significantly increase.

\section{AUTHOR CONTRIBUTIONS}

IC wrote the manuscript. VV and EC critically analyzed and corrected the text. EC came up with the concept.

\section{FUNDING}

This work was supported by Russian Scientific Foundation grant 14-14-00697 and the Russian State Funded Budget Project (\# AAAA-A17-117020210024-8).

\section{ACKNOWLEDGMENTS}

The authors thank Daniil Gladkikh for help preparing the figures.

\section{SUPPLEMENTARY MATERIAL}

The Supplementary Material for this article can be found online at: https://www.frontiersin.org/articles/10.3389/fphar. 2019.00444/full\#supplementary-material

potency and stability compared to unmodified small interfering RNA. J. Med. Chem. 48, 901-904. doi: 10.1021/jm049167j

Alterman, J. F., Hall, L. M., Coles, A. H., Hassler, M. R., Didiot, M. C., Chase, K., et al. (2015). Hydrophobically modified siRNAs silence Huntingtin mRNA in primary neurons and mouse brain. Mol. Ther. Nucleic Acids 4:e266. doi: $10.1038 / \mathrm{mtna} 2015.38$

Amarzguioui, M., Holen, T., Babaie, E., and Prydz, H. (2003). Tolerance for mutations and chemical modifications in a siRNA. Nucleic Acids Res. 31, 589-595. doi: 10.1093/nar/gkg147

Ameres, S. L., Martinez, J., and Schroeder, R. (2007). Molecular basis for target RNA recognition and cleavage by human RISC. Cell. 130, 101-112. doi: 10.1016/j.cell.2007.04.037

Anderson, B. R., Muramatsu, H., Nallagatla, S. R., Bevilacqua, P. C., Sansing, L. H., Weissman, D., et al. (2010). Incorporation of pseudouridine into mRNA enhances translation by diminishing PKR activation. Nucleic Acids Res. 38, 5884-5892. doi: 10.1093/nar/ gkq347

Aronin, N. (2006). Target selectivity in mRNA silencing. Gene Ther. 13, 509-516. doi: 10.1038/sj.gt.3302726 
Barati, S., Chegini, F., Hurtado, P., and Rush, R. A. (2002). Hybrid tetanus toxin $\mathrm{C}$ fragment-diphtheria toxin translocation domain allows specific gene transfer into PC12 cells. Exp. Neurol. 177, 75-87. doi: 10.1006/exnr.2002.7999

Baumer, S., Baumer, N., Appel, N., Terheyden, L., Fremerey, J., Schelhaas, S., et al. (2015). Antibody-mediated delivery of anti-KRAS-siRNA in vivo overcomes therapy resistance in colon cancer. Clin. Cancer Res. 21, 1383-1394. doi: 10.1158/1078-0432.CCR-13-2017

Behlke, M. A. (2008). Chemical modification of siRNAs for in vivo use. Oligonucleotides. 18, 305-319. doi: 10.1089/oli.2008.0164

Benizri, S., Gissot, A., Martin, A., Vialet, B., Grinstaff, M. W., and Barthelemy, P. (2019). Bioconjugated oligonucleotides: recent developments and therapeutic applications. Bioconjug. Chem. 30, 366-383. doi: 10.1021/acs.bioconjchem.8b00761

Bernstein, E., Caudy, A. A., Hammond, S. M., and Hannon, G. J. (2001). Role for a bidentate ribonuclease in the initiation step of RNA interference. Nature. 409, 363-366. doi: 10.1038/35053110

Biscans, A., Coles, A., Haraszti, R., Echeverria, D., Hassler, M., Osborn, M., et al. (2018). Diverse lipid conjugates for functional extra-hepatic siRNA delivery in vivo. Nucleic Acids Res. 47, 1082-1096. doi: 10.1093/nar/gky1239

Blidner, R. A., Hammer, R. P., Lopez, M. J., Robinson, S. O., and Monroe, W. T. (2007). Fully $2^{\prime}$-deoxy-2'-fluoro substituted nucleic acids induce RNA interference in mammalian cell culture. Chem. Biol. Drug Des. 70, 113-122. doi: 10.1111/j.1747-0285.2007.00542.x

Bobst, A. M., Rottman, F., and Cerutti, P. A. (1969). Effect of the methylation of the $2^{\prime}$-hydroxyl groups in polyadenylic acid on its structure in weakly acidic and neutral solutions and on its capability to form ordered complexes with polyuridylic acid. J. Mol. Biol. 46, 221-234. doi: 10.1016/0022-2836(69) 90418-5

Boeckle, S., Wagner, E., and Ogris, M. (2005). C- versus N-terminally linked melittin-polyethylenimine conjugates: the site of linkage strongly influences activity of DNA polyplexes. J. Gene Med. 7, 1335-1347. doi: 10.1002/ jgm.783

Braasch, D. A., Jensen, S., Liu, Y., Kaur, K., Arar, K., White, M. A., et al. (2003). RNA interference in mammalian cells by chemically-modified RNA. Biochemistry. 42, 7967-7975. doi: 10.1021/bi0343774

Bramsen, J. B., Laursen, M. B., Damgaard, C. K., Lena, S. W., Babu, B. R., Wengel, J., et al. (2007). Improved silencing properties using small internally segmented interfering RNAs. Nucleic Acids Res. 35, 5886-5897. doi: 10.1093/nar/gkm548

Bramsen, J. B., Laursen, M. B., Nielsen, A. F., Hansen, T. B., Bus, C., Langkjaer, N., et al. (2009). A large-scale chemical modification screen identifies design rules to generate siRNAs with high activity, high stability and low toxicity. Nucleic Acids Res. 37, 2867-2881. doi: 10.1093/nar/gkp106

Breslow, R., and Chapman, W. H. Jr. (1996). On the mechanism of action of ribonuclease A: relevance of enzymatic studies with a p-nitrophenylphosphate ester and a thiophosphate ester. Proc. Natl. Acad. Sci. U.S.A. 93, 10018-10021. doi: 10.1073/pnas.93.19.10018

Brown, M. S., and Goldstein, J. L. (1976). Receptor-mediated control of cholesterol metabolism. Science. 191, 150-154. doi: 10.1126/science.174194

Brunzell, J. D., Davidson, M., Furberg, C. D., Goldberg, R. B., Howard, B. V., Stein, J. H., et al. (2008). Lipoprotein management in patients with cardiometabolic risk: consensus statement from the American Diabetes Association and the American College of Cardiology Foundation. Diabetes Care. 31, 811-822. doi: $10.2337 / \mathrm{dc} 08-9018$

Byrne, M., Tzekov, R., Wang, Y., Rodgers, A., Cardia, J., Ford, G., et al. (2013). Novel hydrophobically modified asymmetric RNAi compounds (sd-rxRNA) demonstrate robust efficacy in the eye. J. Ocul. Pharmacol. Ther. 29, 855-864. doi: 10.1089/jop.2013.0148

Catuogno, S., Esposito, C. L., Condorelli, G., and de Franciscis, V. (2018). Nucleic acids delivering nucleic acids. Adv. Drug Deliv. Rev. 134, 79-93. doi: 10.1016/j.addr.2018.04.006

Cesarone, G., Edupuganti, O. P., Chen, C. P., and Wickstrom, E. (2007). Insulin receptor substrate 1 knockdown in human MCF7 ER+ breast cancer cells by nuclease-resistant IRS1 siRNA conjugated to a disulfide-bridged D-peptide analogue of insulin-like growth factor 1. Bioconjug. Chem. 18, 1831-1840. doi: $10.1021 / \mathrm{bc} 070135 \mathrm{v}$

Chandradoss, S. D., Schirle, N. T., Szczepaniak, M., MacRae, I. J., and Joo, C. (2015). A dynamic search process underlies microRNA targeting. Cell. 162, 96-107. doi: 10.1016/j.cell.2015.06.032
Chen, C., Yang, Z., and Tang, X. (2018). Chemical modifications of nucleic acid drugs and their delivery systems for gene-based therapy. Med. Res. Rev. 38, 829-869. doi: 10.1002/med.21479

Chen, G., Wang, Y., Xie, R., and Gong, S. (2017). Tumor-targeted pH/redox dualsensitive unimolecular nanoparticles for efficient siRNA delivery. J. Control. Release. 259, 105-114. doi: 10.1016/j.jconrel.2017.01.042

Chen, P. I., Schauer, K., Kong, C., Harding, A. R., Goud, B., and Stahl, P. D. (2014). Rab5 isoforms orchestrate a "division of labor" in the endocytic network; Rab5C modulates Rac-mediated cell motility. PLoS ONE. 9:e90384. doi: 10.1371/journal.pone.0090384

Chen, P. Y., Weinmann, L., Gaidatzis, D., Pei, Y., Zavolan, M., Tuschl, T., et al. (2008). Strand-specific 5'-O-methylation of siRNA duplexes controls guide strand selection and targeting specificity. RNA. 14, 263-274. doi: 10.1261/rna.789808

Chen, Q., Butler, D., Querbes, W., Pandey, R. K., Ge, P., Maier, M. A., et al. (2010). Lipophilic siRNAs mediate efficient gene silencing in oligodendrocytes with direct CNS delivery. J. Control. Release. 144, 227-232. doi: 10.1016/j.jconrel.2010.02.011

Chernikov, I. V., Gladkikh, D. V., Meschaninova, M. I., Karelina, U. A., Ven'yaminova, A. G., Zenkova, M. A., et al. (2018). Fluorophore labeling affects the cellular accumulation and gene silencing activity of cholesterolmodified small interfering RNAs in vitro. Nucleic Acid Ther. 29, 33-43. doi: 10.1089/nat.2018.0745

Chernikov, I. V., Gladkikh, D. V., Meschaninova, M. I., Ven'yaminova, A. G., Zenkova, M. A., Vlassov, V. V., et al. (2017). Cholesterolcontaining nuclease-resistant siRNA accumulates in tumors in a carrierfree mode and silences MDR1 gene. Mol. Ther. Nucleic Acids 6, 209-220. doi: 10.1016/j.omtn.2016.12.011

Chiu, Y. L., Ali, A., Chu, C. Y., Cao, H., and Rana, T. M. (2004). Visualizing a correlation between siRNA localization, cellular uptake, and RNAi in living cells. Chem. Biol. 11, 1165-1175. doi: 10.1016/j.chembiol.2004.06.006

Chiu, Y. L., and Rana, T. M. (2003). siRNA function in RNAi: a chemical modification analysis. RNA. 9, 1034-1048. doi: 10.1261/rna.5103703

Console, S., Marty, C., Garcia-Echeverria, C., Schwendener, R., and BallmerHofer, K. (2003). Antennapedia and HIV transactivator of transcription (TAT) "protein transduction domains" promote endocytosis of high molecular weight cargo upon binding to cell surface glycosaminoglycans. J. Biol. Chem. 278, 35109-35114. doi: 10.1074/jbc.M301726200

Crooke, S. T., Witztum, J. L., Bennett, C. F., and Baker, B. F. (2018). RNA-targeted therapeutics. Cell Metab. 27, 714-739. doi: 10.1016/j.cmet.2018.03.004

Cuellar, T. L., Barnes, D., Nelson, C., Tanguay, J., Yu, S. F., Wen, X., et al. (2014). Systematic evaluation of antibody-mediated siRNA delivery using an industrial platform of THIOMAB-siRNA conjugates. Nucleic Acids Res. 43, 1189-1203. doi: 10.1093/nar/gku1362

Cummins, L. L., Owens, S. R., Risen, L. M., Lesnik, E. A., Freier, S. M., McGee, D., et al. (1995). Characterization of fully $2^{\prime}$-modified oligoribonucleotide heteroand homoduplex hybridization and nuclease sensitivity. Nucleic Acids Res. 23, 2019-2024.

Czauderna, F., Fechtner, M., Dames, S., Aygun, H., Klippel, A., Pronk, G. J., et al. (2003). Structural variations and stabilising modifications of synthetic siRNAs in mammalian cells. Nucleic Acids Res. 31, 2705-2716. doi: 10.1093/nar/gkg393

Damha, M. J., Noronha, A. M., Wilds, C. J., Trempe, J. F., Denisov, A., Pon, R. T., et al. (2001). Properties of arabinonucleic acids (ANA \& 20'F-ANA): implications for the design of antisense therapeutics that invoke RNase H cleavage of RNA. Nucleosides Nucleotides Nucleic Acids. 20, 429-440. doi: $10.1081 / \mathrm{NCN}-100002317$

Dande, P., Prakash, T. P., Sioufi, N., Gaus, H., Jarres, R., Berdeja, A., et al. (2006). Improving RNA interference in mammalian cells by $4^{\prime}$-thio-modified small interfering RNA (siRNA): effect on siRNA activity and nuclease stability when used in combination with 2 '-O-alkyl modifications. J. Med. Chem. 49, 1624-1634. doi: 10.1021/jm050822c

Dassie, J. P., Liu, X. Y., Thomas, G. S., Whitaker, R. M., Thiel, K. W., Stockdale, K. R., et al. (2009). Systemic administration of optimized aptamer-siRNA chimeras promotes regression of PSMA-expressing tumors. Nat. Biotechnol. 27, 839-849. doi: $10.1038 /$ nbt.1560

De Paula, D., Bentley, M. V., and Mahato, R. I. (2007). Hydrophobization and bioconjugation for enhanced siRNA delivery and targeting. RNA. 13, 431-456. doi: $10.1261 /$ rna.459807 
Deleavey, G. F., and Damha, M. J. (2012). Designing chemically modified oligonucleotides for targeted gene silencing. Chem. Biol. 19, 937-954. doi: 10.1016/j.chembiol.2012.07.011

Deleavey, G. F., Watts, J. K., Alain, T., Robert, F., Kalota, A., Aishwarya, V., et al. (2010). Synergistic effects between analogs of DNA and RNA improve the potency of siRNA-mediated gene silencing. Nucleic Acids Res. 38, 4547-4557. doi: $10.1093 /$ nar/gkq181

Dorn, G., Patel, S., Wotherspoon, G., Hemmings-Mieszczak, M., Barclay, J., Natt, F. J., et al. (2004). siRNA relieves chronic neuropathic pain. Nucleic Acids Res. 32:e49. doi: 10.1093/nar/gnh044

Dovydenko, I., Tarassov, I., Venyaminova, A., and Entelis, N. (2016). Method of carrier-free delivery of therapeutic RNA importable into human mitochondria: Lipophilic conjugates with cleavable bonds. Biomaterials. 76, 408-417. doi: 10.1016/j.biomaterials.2015.10.075

Dowler, T., Bergeron, D., Tedeschi, A. L., Paquet, L., Ferrari, N., and Damha, M. J. (2006). Improvements in siRNA properties mediated by $2^{\prime}$-deoxy-2' fluoro-beta-D-arabinonucleic acid (FANA). Nucleic Acids Res. 34, 1669-1675. doi: $10.1093 /$ nar/gkl033

Dubey, P. K., Mishra, V., Jain, S., Mahor, S., and Vyas, S. P. (2004). Liposomes modified with cyclic RGD peptide for tumor targeting. J. Drug Target. 12, 257-264. doi: 10.1080/10611860410001728040

Eberle, F., Giessler, K., Deck, C., Heeg, K., Peter, M., Richert, C., et al. (2008). Modifications in small interfering RNA that separate immunostimulation from RNA interference. J. Immunol. 180, 3229-3237. doi: 10.4049/jimmunol.180.5.3229

Eckstein, F. (1970). Nucleoside phosphorothioates. J. Am. Chem. Soc. 92, 4718-4723. doi: 10.1111/j.1432-1033.1970.tb00961.x

Eckstein, F. (2014). Phosphorothioates, essential components of therapeutic oligonucleotides. Nucleic Acid Ther. 24, 374-387. doi: 10.1089/nat.2014.0506

El-Andaloussi, S., Jarver, P., Johansson, H. J., and Langel, U. (2007). Cargodependent cytotoxicity and delivery efficacy of cell-penetrating peptides: a comparative study. Biochem. J. 407, 285-292. doi: 10.1042/BJ20070507

Elbashir, S. M., Martinez, J., Patkaniowska, A., Lendeckel, W., and Tuschl, T. (2001). Functional anatomy of siRNAs for mediating efficient RNAi in Drosophila melanogaster embryo lysate. EMBO J. 20, 6877-6888. doi: 10.1093/emboj/20.23.6877

Elkayam, E., Parmar, R., Brown, C. R., Willoughby, J. L., Theile, C. S., Manoharan, M., et al. (2017). siRNA carrying an (E)-vinylphosphonate moiety at the 5 end of the guide strand augments gene silencing by enhanced binding to human Argonaute-2. Nucleic Acids Res. 45, 3528-3536. doi: 10.1093/nar/gkw1171

Elmen, J., Thonberg, H., Ljungberg, K., Frieden, M., Westergaard, M., Xu, Y., et al. (2005). Locked nucleic acid (LNA) mediated improvements in siRNA stability and functionality. Nucleic Acids Res. 33, 439-447. doi: 10.1093/nar/gki193

Esposito, C. L., Nuzzo, S., Catuogno, S., Romano, S., de Nigris, F., and de Franciscis, V. (2018). STAT3 Gene silencing by aptamer-siRNA chimera as selective therapeutic for glioblastoma. Mol. Ther. Nucleic Acids 10, 398-411. doi: 10.1016/j.omtn.2017.12.021

Esposito, C. L., Nuzzo, S., Kumar, S. A., Rienzo, A., Lawrence, C. L., Pallini, R., et al. (2016). A combined microRNA-based targeted therapeutic approach to eradicate glioblastoma stem-like cells. J. Control. Release. 238, 43-57. doi: 10.1016/j.jconrel.2016.07.032

Feinberg, E. H., and Hunter, C. P. (2003). Transport of dsRNA into cells by the transmembrane protein SID-1. Science. 301, 1545-1547. doi: $10.1126 /$ science. 1087117

Findlay, D., Herries, D. G., Mathias, A. P., Rabin, B. R., and Ross, C. A. (1962). The active site and mechanism of action of bovine pancreatic ribonuclease. 7 . The catalytic mechanism. Biochem. J. 85, 152-153.

Fire, A., Xu, S., Montgomery, M. K., Kostas, S. A., Driver, S. E., and Mello, C. C. (1998). Potent and specific genetic interference by double-stranded RNA in Caenorhabditis elegans. Nature. 391, 806-811.

Fisher, M., Abramov, M., Van Aerschot, A., Rozenski, J., Dixit, V., Juliano, R. L., et al. (2009). Biological effects of hexitol and altritol-modified siRNAs targeting B-Raf. Eur. J. Pharmacol. 606, 38-44. doi: 10.1016/j.ejphar.2009.01.030

Fisher, M., Abramov, M., Van Aerschot, A., Xu, D., Juliano, R. L., and Herdewijn, P. (2007). Inhibition of MDR1 expression with altritol-modified siRNAs. Nucleic Acids Res. 35, 1064-1074. doi: 10.1093/nar/gkl1126

Foster, D. J., Brown, C. R., Shaikh, S., Trapp, C., Schlegel, M. K., Qian, $\mathrm{K}$., et al. (2018). Advanced siRNA designs further improve in vivo performance of GalNAc-siRNA conjugates. Mol. Ther. 26, 708-717. doi: 10.1016/j.ymthe.2017.12.021

Frank, F., Sonenberg, N., and Nagar, B. (2010). Structural basis for $5^{\prime}$-nucleotide base-specific recognition of guide RNA by human AGO2. Nature. 465, 818-822. doi: 10.1038/nature09039

Frazao, C., McVey, C. E., Amblar, M., Barbas, A., Vonrhein, C., Arraiano, C. M., et al. (2006). Unravelling the dynamics of RNA degradation by ribonuclease II and its RNA-bound complex. Nature. 443, 110-114. doi: 10.1038/ nature 05080

Fucini, R. V., Haringsma, H. J., Deng, P., Flanagan, W. M., and Willingham, A. T. (2012). Adenosine modification may be preferred for reducing siRNA immune stimulation. Nucleic Acid Ther. 22, 205-210. doi: 10.1089/nat.2011.0334

Gagat, M., Zielinska, W., and Grzanka, A. (2017). Cell-penetrating peptides and their utility in genome function modifications. Int. J. Mol. Med. 40, 1615-1623. doi: $10.3892 /$ ijmm.2017.3172

Garber, K. (2016). Alnylam terminates revusiran program, stock plunges. Nat. Biotechnol. 34, 1213-1214. doi: 10.1038/nbt1216-1213

Garber, K. (2018). Alnylam launches era of RNAi drugs. Nat. Biotechnol. 36, 777-778. doi: 10.1038/nbt0918-777

Gilleron, J., Paramasivam, P., Zeigerer, A., Querbes, W., Marsico, G., Andree, C., et al. (2015). Identification of siRNA delivery enhancers by a chemical library screen. Nucleic Acids Res. 43, 7984-8001. doi: 10.1093/nar/gkv762

Goldstein, J. L., Brown, M. S., Anderson, R. G., Russell, D. W., and Schneider, W. J. (1985). Receptor-mediated endocytosis: concepts emerging from the LDL receptor system. Annu. Rev. Cell Biol. 1, 1-39. doi: 10.1146/annurev.cb.01.110185.000245

Gore, K. R., Nawale, G. N., Harikrishna, S., Chittoor, V. G., Pandey, S. K., Hobartner, C., et al. (2012). Synthesis, gene silencing, and molecular modeling studies of $4^{\prime}$-C-aminomethyl-2' -O-methyl modified small interfering RNAs. J. Org. Chem. 77, 3233-3245. doi: 10.1021/jo202666m

Goyenvalle, A., Griffith, G., Babbs, A., El Andaloussi, S., Ezzat, K., Avril, A., et al. (2015). Functional correction in mouse models of muscular dystrophy using exon-skipping tricyclo-DNA oligomers. Nat. Med. 21, 270-275. doi: 10.1038/nm.3765

Haley, B., and Zamore, P. D. (2004). Kinetic analysis of the RNAi enzyme complex. Nat. Struct. Mol. Biol. 11, 599-606. doi: 10.1038/nsmb780

Hall, A. H., Wan, J., Shaughnessy, E. E., Ramsay Shaw, B., and Alexander, K. A. (2004). RNA interference using boranophosphate siRNAs: structureactivity relationships. Nucleic Acids Res. 32, 5991-6000. doi: 10.1093/nar/ gkh936

Hall, A. H., Wan, J., Spesock, A., Sergueeva, Z., Shaw, B. R., and Alexander, K. A. (2006). High potency silencing by single-stranded boranophosphate siRNA. Nucleic Acids Res. 34, 2773-2781. doi: 10.1093/nar/gkl339

Hamil, A. S., and Dowdy, S. F. (2016). Synthesis and conjugation of small interfering ribonucleic neutral SiRNNs. Methods Mol. Biol. 1364, 1-9. doi: 10.1007/978-1-4939-3112-5_1

Haraszti, R. A., Roux, L., Coles, A. H., Turanov, A. A., Alterman, J. F., Echeverria, D., et al. (2017). 5-Vinylphosphonate improves tissue accumulation and efficacy of conjugated siRNAs in vivo. Nucleic Acids Res. 45, 7581-7592. doi: $10.1093 /$ nar/gkx507

Harborth, J., Elbashir, S. M., Vandenburgh, K., Manninga, H., Scaringe, S. A., Weber, K., et al. (2003). Sequence, chemical, and structural variation of small interfering RNAs and short hairpin RNAs and the effect on mammalian gene silencing. Antisense Nucleic Acid Drug Dev. 13, 83-105. doi: 10.1089/108729003321629638

Harp, J. M., Guenther, D. C., Bisbe, A., Perkins, L., Matsuda, S., Bommineni, G. R., et al. (2018). Structural basis for the synergy of $4^{\prime}$ - and $2^{\prime}$-modifications on siRNA nuclease resistance, thermal stability and RNAi activity. Nucleic Acids Res. 46, 8090-8104. doi: 10.1093/nar/gky703

Hassler, M. R., Turanov, A. A., Alterman, J. F., Haraszti, R. A., Coles, A. H., Osborn, M. F., et al. (2018). Comparison of partially and fully chemically-modified siRNA in conjugate-mediated delivery in vivo. Nucleic Acids Res. 46, 2185-2196. doi: $10.1093 /$ nar/gky037

Heitz, F., Morris, M. C., and Divita, G. (2009). Twenty years of cell-penetrating peptides: from molecular mechanisms to therapeutics. Br. J. Pharmacol. 157, 195-206. doi: 10.1111/j.1476-5381.2009.00057.x

Henry, S. P., Beattie, G., Yeh, G., Chappel, A., Giclas, P., Mortari, A., et al. (2002). Complement activation is responsible for acute toxicities in rhesus monkeys 
treated with a phosphorothioate oligodeoxynucleotide. Int. Immunopharmacol. 2, 1657-1666. doi: 10.1016/S1567-5769(02)00142-X

Herdewijn, P., and Juliano, R. (2007). Nucleic acids with a six-membered carbohydrate mimic and RNA interference. Blood Cells Mol. Dis. 38, 100-101. doi: 10.1016/j.bcmd.2006.10.005

Hoerter, J. A., and Walter, N. G. (2007). Chemical modification resolves the asymmetry of siRNA strand degradation in human blood serum. RNA. 13, 1887-1893. doi: 10.1261/rna.602307

Hong, C. A., and Nam, Y. S. (2016). Reducible dimeric conjugates of small internally segment interfering RNA for efficient gene silencing. Macromol. Biosci. 16, 1442-1449. doi: 10.1002/mabi.201600137

Hori, S. I., Herrera, A., Rossi, J. J., and Zhou, J. (2018). Current advances in aptamers for cancer diagnosis and therapy. Cancers (Basel). 10:9. doi: 10.3390/cancers 10010009

Hoshika, S., Minakawa, N., Kamiya, H., Harashima, H., and Matsuda, A. (2005). RNA interference induced by siRNAs modified with $4^{\prime}$ thioribonucleosides in cultured mammalian cells. FEBS Lett. 579, 3115-3118. doi: 10.1016/j.febslet.2005.04.073

Hoshika, S., Minakawa, N., Shionoya, A., Imada, K., Ogawa, N., and Matsuda, A. (2007). Study of modification pattern-RNAi activity relationships by using siRNAs modified with $4^{\prime}$-thioribonucleosides. Chembiochem. 8, 2133-2138. doi: 10.1002/cbic.200700342

Hossain, D. M., Dos Santos, C., Zhang, Q., Kozlowska, A., Liu, H., Gao, C., et al. (2014). Leukemia cell-targeted STAT3 silencing and TLR9 triggering generate systemic antitumor immunity. Blood. 123, 15-25. doi: 10.1182/blood-2013-07-517987

Hsu, C. L., and Stevens, A. (1993). Yeast cells lacking $5^{\prime}->3^{\prime}$ exoribonuclease 1 contain mRNA species that are poly(A) deficient and partially lack the $5^{\prime}$ cap structure. Mol. Cell. Biol. 13, 4826-4835.

Hsu, T., and Mitragotri, S. (2011). Delivery of siRNA and other macromolecules into skin and cells using a peptide enhancer. Proc. Natl. Acad. Sci. U.S.A. 108, 15816-15821. doi: 10.1073/pnas.1016152108

Huang, Y. (2017). Preclinical and clinical advances of GalNAc-decorated nucleic acid therapeutics. Mol. Ther. Nucleic Acids 6, 116-132. doi: 10.1016/j.omtn.2016.12.003

Huntzinger, E., and Izaurralde, E. (2011). Gene silencing by microRNAs: contributions of translational repression and mRNA decay. Nat. Rev. Genet. 12, 99-110. doi: 10.1038/nrg2936

Iannitti, T., Morales-Medina, J. C., and Palmieri, B. (2014). Phosphorothioate oligonucleotides: effectiveness and toxicity. Curr. Drug Targets. 15, 663-673. doi: $10.2174 / 1389450115666140321100304$

Ibtehaj, N., and Huda, R. (2017). High-dose BAFF receptor specific mAb-siRNA conjugate generates Fas-expressing B cells in lymph nodes and high-affinity serum autoantibody in a myasthenia mouse model. Clin. Immunol. 176, 122-130. doi: 10.1016/j.clim.2017.01.005

Ireson, C. R., and Kelland, L. R. (2006). Discovery and development of anticancer aptamers. Mol. Cancer Ther. 5, 2957-2962. doi: 10.1158/1535-7163.MCT-06-0172

Iwase, R., Toyama, T., and Nishimori, K. (2007). Solid-phase synthesis of modified RNAs containing amide-linked oligoribonucleosides at their $3^{\prime}$-end and their application to siRNA. Nucleosides Nucleotides Nucleic Acids. 26, 1451-1454. doi: 10.1080/15257770701542389

Jackson, A. L., Burchard, J., Leake, D., Reynolds, A., Schelter, J., Guo, J., et al. (2006). Position-specific chemical modification of siRNAs reduces "off-target" transcript silencing. RNA 12, 1197-1205. doi: 10.1261/rna. 30706

Janas, M. M., Jiang, Y., Schlegel, M. K., Waldron, S., Kuchimanchi, S., and Barros, S. A. (2017). Impact of oligonucleotide structure, chemistry, and delivery method on in vitro cytotoxicity. Nucleic Acid Ther. 27, 11-22. doi: $10.1089 /$ nat.2016.0639

Janas, M. M., Schlegel, M. K., Harbison, C. E., Yilmaz, V. O., Jiang, Y., Parmar, R., et al. (2018). Selection of GalNAc-conjugated siRNAs with limited off-target-driven rat hepatotoxicity. Nat. Commun. 9:723. doi: 10.1038/s41467-018-02989-4

Jensen, T. B., Langkjaer, N., and Wengel, J. (2008). Unlocked nucleic acid (UNA) and UNA derivatives: thermal denaturation studies. Nucleic Acids Symp. Ser. (Oxf)., 133-134. doi: 10.1093/nass/nrn068
Jinek, M., and Doudna, J. A. (2009). A three-dimensional view of the molecular machinery of RNA interference. Nature. 457, 405-412. doi: $10.1038 /$ nature 07755

Judge, A. D., Bola, G., Lee, A. C., and MacLachlan, I. (2006). Design of noninflammatory synthetic siRNA mediating potent gene silencing in vivo. Mol. Ther. 13, 494-505. doi: 10.1016/j.ymthe.2005.11.002

Julien, K. R., Sumita, M., Chen, P. H., Laird-Offringa, I. A., and Hoogstraten, C. G. (2008). Conformationally restricted nucleotides as a probe of structurefunction relationships in RNA. RNA. 14, 1632-1643. doi: 10.1261/rna.866408

Kanasty, R. L., Whitehead, K. A., Vegas, A. J., and Anderson, D. G. (2012). Action and reaction: the biological response to siRNA and its delivery vehicles. Mol. Ther. 20, 513-524. doi: 10.1038/mt.2011.294

Kannan, A., and Burrows, C. J. (2011). Synthesis of N2-alkyl-8-oxo-7,8-dihydro2 -deoxyguanosine derivatives and effects of these modifications on RNA duplex stability. J. Org. Chem. 76, 720-723. doi: 10.1021/jo102187y

Kel'in, A. V., Zlatev, I., Harp, J., Jayaraman, M., Bisbe, A., O’Shea, J., et al. (2016). Structural basis of duplex thermodynamic stability and enhanced nuclease resistance of $5^{\prime}$-C-methyl pyrimidine-modified oligonucleotides. J. Org. Chem. 81, 2261-2279. doi: 10.1021/acs.joc.5b02375

Kenski, D. M., Butora, G., Willingham, A. T., Cooper, A. J., Fu, W., Qi, N., et al. (2012). siRNA-optimized modifications for enhanced in vivo activity. Mol. Ther. Nucleic Acids 1:e5. doi: 10.1038/mtna.2011.4

Khan, T., Weber, H., DiMuzio, J., Matter, A., Dogdas, B., Shah, T., et al. (2016). Silencing myostatin using cholesterol-conjugated siRNAs induces muscle growth. Mol. Ther. Nucleic Acids. 5:e342. doi: 10.1038/mtna.2016.55

Khvorova, A. (2017). Oligonucleotide therapeutics-a new class of cholesterollowering drugs. N. Engl. J. Med. 376, 4-7. doi: 10.1056/NEJMp1614154

Khvorova, A., Reynolds, A., and Jayasena, S. D. (2003). Functional siRNAs and miRNAs exhibit strand bias. Cell. 115, 209-216. doi: 10.1016/S0092-8674(03)00801-8

Khvorova, A., and Watts, J. K. (2017). The chemical evolution of oligonucleotide therapies of clinical utility. Nat. Biotechnol. 35, 238-248. doi: 10.1038/nbt.3765

Koehn, S., Schaefer, H. W., Ludwig, M., Haag, N., Schubert, U. S., Seyfarth, L., et al. (2010). Cell-specific RNA interference by peptide-inhibited-peptidaseactivated siRNAs. J. RNAi Gene Silencing 6, 422-430.

Koller, E., Propp, S., Murray, H., Lima, W., Bhat, B., Prakash, T. P., et al. (2006). Competition for RISC binding predicts in vitro potency of siRNA. Nucleic Acids Res. 34, 4467-4476. doi: 10.1093/nar/gkl589

Kolosenko, I., Edsbacker, E., Bjorklund, A. C., Hamil, A. S., Goroshchuk, O., Grander, D., et al. (2017). RNAi prodrugs targeting Plk1 induce specific gene silencing in primary cells from pediatric T-acute lymphoblastic leukemia patients. J. Control. Release 261, 199-206. doi: 10.1016/j.jconrel.2017.07.002

Kordasiewicz, H. B., Stanek, L. M., Wancewicz, E. V., Mazur, C., McAlonis, M. M., Pytel, K. A., et al. (2012). Sustained therapeutic reversal of Huntington's disease by transient repression of huntingtin synthesis. Neuron. 74, 1031-1044. doi: 10.1016/j.neuron.2012.05.009

Kortylewski, M., Swiderski, P., Herrmann, A., Wang, L., Kowolik, C., Kujawski, M., et al. (2009). In vivo delivery of siRNA to immune cells by conjugation to a TLR9 agonist enhances antitumor immune responses. Nat. Biotechnol. 27, 925-932. doi: $10.1038 /$ nbt.1564

Kwiatkowska, A., Sobczak, M., Mikolajczyk, B., Janczak, S., Olejniczak, A. B., Sochacki, M., et al. (2013). siRNAs modified with boron cluster and their physicochemical and biological characterization. Bioconjug. Chem. 24, 1017-1026. doi: 10.1021/bc400059y

Lai, W. Y., Wang, W. Y., Chang, Y. C., Chang, C. J., Yang, P. C., and Peck, K. (2014). Synergistic inhibition of lung cancer cell invasion, tumor growth and angiogenesis using aptamer-siRNA chimeras. Biomaterials. 35, 2905-2914. doi: 10.1016/j.biomaterials.2013.12.054

Lakadamyali, M., Rust, M. J., and Zhuang, X. (2006). Ligands for clathrinmediated endocytosis are differentially sorted into distinct populations of early endosomes. Cell. 124, 997-1009. doi: 10.1016/j.cell.2005.12.038

Langkjaer, N., Pasternak, A., and Wengel, J. (2009). UNA (unlocked nucleic acid): a flexible RNA mimic that allows engineering of nucleic acid duplex stability. Bioorg. Med. Chem. 17, 5420-5425. doi: 10.1016/j.bmc.2009.06.045

Lau, S., Graham, B., Cao, N., Boyd, B. J., Pouton, C. W., and White, P. J. (2012). Enhanced extravasation, stability and in vivo cardiac gene silencing via in situ siRNA-albumin conjugation. Mol. Pharm. 9, 71-80. doi: 10.1021/mp2002522 
Laursen, M. B., Pakula, M. M., Gao, S., Fluiter, K., Mook, O. R., Baas, F., et al. (2010). Utilization of unlocked nucleic acid (UNA) to enhance siRNA performance in vitro and in vivo. Mol. Biosyst. 6, 862-870. doi: $10.1039 / \mathrm{b} 918869 \mathrm{j}$

Lee, M., Simon, A. D., Stein, C. A., and Rabbani, L. E. (1999). Antisense strategies to inhibit restenosis. Antisense Nucleic Acid Drug Dev. 9, 487-492. doi: 10.1089/oli.1.1999.9.487

Lee, S. H., Castagner, B., and Leroux, J. C. (2013). Is there a future for cellpenetrating peptides in oligonucleotide delivery? Eur. J. Pharm. Biopharm. 85, 5-11. doi: 10.1016/j.ejpb.2013.03.021

Lee, S. H., Kang, Y. Y., Jang, H. E., and Mok, H. (2016). Current preclinical small interfering RNA (siRNA)-based conjugate systems for RNA therapeutics. $A d v$. Drug Deliv. Rev. 104, 78-92. doi: 10.1016/j.addr.2015.10.009

Lee, Y. J., Johnson, G., Peltier, G. C., and Pellois, J. P. (2011). A HA2-Fusion tag limits the endosomal release of its protein cargo despite causing endosomal lysis. Biochim. Biophys. Acta. 1810, 752-758. doi: 10.1016/j.bbagen.2011.05.013

Lee, Y. S., Pressman, S., Andress, A. P., Kim, K., White, J. L., Cassidy, J. J., et al. (2009). Silencing by small RNAs is linked to endosomal trafficking. Nat. Cell Biol. 11, 1150-1156. doi: 10.1038/ncb1930

Lemaitre, M., Bayard, B., and Lebleu, B. (1987). Specific antiviral activity of a poly(L-lysine)-conjugated oligodeoxyribonucleotide sequence complementary to vesicular stomatitis virus $\mathrm{N}$ protein mRNA initiation site. Proc. Natl. Acad. Sci. U.S.A. 84, 648-652. doi: 10.1073/pnas.84.3.648

Letsinger, R. L., Zhang, G. R., Sun, D. K., Ikeuchi, T., and Sarin, P. S. (1989). Cholesteryl-conjugated oligonucleotides: synthesis, properties, and activity as inhibitors of replication of human immunodeficiency virus in cell culture. Proc. Natl. Acad. Sci. U.S.A. 86, 6553-6556. doi: 10.1073/pnas.86.17.6553

Leuschner, P. J., Ameres, S. L., Kueng, S., and Martinez, J. (2006). Cleavage of the siRNA passenger strand during RISC assembly in human cells. EMBO Rep. 7, 314-320. doi: 10.1038/sj.embor.7400637

Lima, W. F., Prakash, T. P., Murray, H. M., Kinberger, G. A., Li, W., Chappell, A. E., et al. (2012). Single-stranded siRNAs activate RNAi in animals. Cell. 150, 883-894. doi: 10.1016/j.cell.2012.08.014

Liu, J., Carmell, M. A., Rivas, F. V., Marsden, C. G., Thomson, J. M., Song, J. J., et al. (2004). Argonaute2 is the catalytic engine of mammalian RNAi. Science. 305, 1437-1441. doi: 10.1126/science. 1102513

Liu, X., Wang, W., Samarsky, D., Liu, L., Xu, Q., Zhang, W., et al. (2014). Tumortargeted in vivo gene silencing via systemic delivery of cRGD-conjugated siRNA. Nucleic Acids Res. 42, 11805-11817. doi: 10.1093/nar/gku831

Lorenz, C., Hadwiger, P., John, M., Vornlocher, H. P., and Unverzagt, C. (2004). Steroid and lipid conjugates of siRNAs to enhance cellular uptake and gene silencing in liver cells. Bioorg. Med. Chem. Lett. 14, 4975-4977. doi: 10.1016/j.bmcl.2004.07.018

Low, P. S., Henne, W. A., and Doorneweerd, D. D. (2008). Discovery and development of folic-acid-based receptor targeting for imaging and therapy of cancer and inflammatory diseases. Acc. Chem. Res. 41, 120-129. doi: 10.1021/ar7000815

Ly, S., Navaroli, D. M., Didiot, M. C., Cardia, J., Pandarinathan, L., Alterman, J. F., et al. (2017). Visualization of self-delivering hydrophobically modified siRNA cellular internalization. Nucleic Acids Res. 45, 15-25. doi: 10.1093/nar/gkw1005

Ma, J. B., Ye, K., and Patel, D. J. (2004). Structural basis for overhang-specific small interfering RNA recognition by the PAZ domain. Nature. 429, 318-322. doi: 10.1038/nature02519

Ma, Y., Kowolik, C. M., Swiderski, P. M., Kortylewski, M., Yu, H., Horne, D. A., et al. (2011). Humanized Lewis-Y specific antibody based delivery of STAT3 siRNA. ACS Chem. Biol. 6, 962-970. doi: 10.1021/cb200176v

Manoharan, M. (2004). RNA interference and chemically modified small interfering RNAs. Curr. Opin. Chem. Biol. 8, 570-579. doi: 10.1016/j.cbpa.2004.10.007

Manoharan, M., Akinc, A., Pandey, R. K., Qin, J., Hadwiger, P., John, M., et al. (2011). Unique gene-silencing and structural properties of 2'-fluoro-modified siRNAs. Angew. Chem. Int. Ed Engl. 50, 2284-2288. doi: 10.1002/anie.201006519

Mansoori, B., Mohammadi, A., Shir Jang, S., and Baradaran, B. (2016). Mechanisms of immune system activation in mammalians by small interfering RNA (siRNA). Artif. Cells Nanomed. Biotechnol. 44, 1589-1596. doi: $10.3109 / 21691401.2015 .1102738$
McNamara, J. O. II, Andrechek, E. R., Wang, Y., Viles, K. D., Rempel, R. E., Gilboa, E., et al. (2006). Cell type-specific delivery of siRNAs with aptamer-siRNA chimeras. Nat. Biotechnol. 24, 1005-1015. doi: 10.1038/nbt1223

Meade, B. R., Gogoi, K., Hamil, A. S., Palm-Apergi, C., van den Berg, A., Hagopian, J. C., et al. (2014). Efficient delivery of RNAi prodrugs containing reversible charge-neutralizing phosphotriester backbone modifications. Nat. Biotechnol. 32, 1256-1261. doi: 10.1038/nbt.3078

Mendez-Acevedo, K. M., Valdes, V. J., Asanov, A., and Vaca, L. (2017). A novel family of mammalian transmembrane proteins involved in cholesterol transport. Sci. Rep. 7:7450. doi: 10.1038/s41598-017-07077-z

Meyer, M., Dohmen, C., Philipp, A., Kiener, D., Maiwald, G., Scheu, C., et al. (2009). Synthesis and biological evaluation of a bioresponsive and endosomolytic siRNA-polymer conjugate. Mol. Pharm. 6, 752-762. doi: $10.1021 / \mathrm{mp} 9000124$

Mook, O., Vreijling, J., Wengel, S. L., Wengel, J., Zhou, C., Chattopadhyaya, J., et al. (2010). In vivo efficacy and off-target effects of locked nucleic acid (LNA) and unlocked nucleic acid (UNA) modified siRNA and small internally segmented interfering RNA (sisiRNA) in mice bearing human tumor xenografts. Artif. DNA PNA XNA. 1, 36-44. doi: 10.4161/adna.1.1.12204

Mook, O. R., Baas, F., de Wissel, M. B., and Fluiter, K. (2007). Evaluation of locked nucleic acid-modified small interfering RNA in vitro and in vivo. Mol. Cancer Ther. 6, 833-843. doi: 10.1158/1535-7163.MCT-06-0195

Moschos, S. A., Jones, S. W., Perry, M. M., Williams, A. E., Erjefalt, J. S., Turner, J. J., et al. (2007). Lung delivery studies using siRNA conjugated to TAT(48-60) and penetratin reveal peptide induced reduction in gene expression and induction of innate immunity. Bioconjug. Chem. 18, 1450-1459. doi: 10.1021/bc070077d

Muhonen, P., Tennila, T., Azhayeva, E., Parthasarathy, R. N., Janckila, A. J., Vaananen, H. K., et al. (2007). RNA interference tolerates 2 '-fluoro modifications at the Argonaute2 cleavage site. Chem. Biodivers. 4, 858-873. doi: 10.1002/cbdv.200790073

Muratovska, A., and Eccles, M. R. (2004). Conjugate for efficient delivery of short interfering RNA (siRNA) into mammalian cells. FEBS Lett. 558, 63-68. doi: 10.1016/S0014-5793(03)01505-9

Mutisya, D., Hardcastle, T., Cheruiyot, S. K., Pallan, P. S., Kennedy, S. D., Egli, M., et al. (2017). Amide linkages mimic phosphates in RNA interactions with proteins and are well tolerated in the guide strand of short interfering RNAs. Nucleic Acids Res. 45, 8142-8155. doi: 10.1093/nar/gkx558

Nair, J. K., Attarwala, H., Sehgal, A., Wang, Q., Aluri, K., Zhang, X., et al. (2017). Impact of enhanced metabolic stability on pharmacokinetics and pharmacodynamics of GalNAc-siRNA conjugates. Nucleic Acids Res. 45, 10969-10977. doi: 10.1093/nar/gkx818

Nair, J. K., Willoughby, J. L., Chan, A., Charisse, K., Alam, M. R., Wang, Q., et al. (2014). Multivalent N-acetylgalactosamine-conjugated siRNA localizes in hepatocytes and elicits robust RNAi-mediated gene silencing. J. Am. Chem. Soc. 136, 16958-16961. doi: 10.1021/ja505986a

Nakanishi, K. (2016). Anatomy of RISC: how do small RNAs and chaperones activate Argonaute proteins? Wiley Interdiscip. Rev. RNA. 7, 637-660. doi: 10.1002/wrna.1356

Nauwelaerts, K., Fisher, M., Froeyen, M., Lescrinier, E., Aerschot, A. V., Xu, D., et al. (2007). Structural characterization and biological evaluation of small interfering RNAs containing cyclohexenyl nucleosides. J. Am. Chem. Soc. 129, 9340-9348. doi: 10.1021/ja067047q

Nechaev, S., Gao, C., Moreira, D., Swiderski, P., Jozwiak, A., Kowolik, C. M., et al. (2013). Intracellular processing of immunostimulatory CpG-siRNA: toll-like receptor 9 facilitates siRNA dicing and endosomal escape. J. Control. Release. 170, 307-315. doi: 10.1016/j.jconrel.2013.06.007

Neff, C. P., Zhou, J., Remling, L., Kuruvilla, J., Zhang, J., Li, H., et al. (2011). An aptamer-siRNA chimera suppresses HIV-1 viral loads and protects from helper CD4(+) T cell decline in humanized mice. Sci. Transl. Med. 3:66ra66. doi: 10.1126/scitranslmed.3001581

Nguyen, T. A., Smith, B. R. C., Tate, M. D., Belz, G. T., Barrios, M. H., Elgass, K. D., et al. (2017). SIDT2 transports extracellular dsRNA into the cytoplasm for innate immune recognition. Immunity. 47, 498-509 e496. doi: 10.1016/j.immuni.2017.08.007

Ni, X., Zhang, Y., Ribas, J., Chowdhury, W. H., Castanares, M., Zhang, Z., et al. (2011). Prostate-targeted radiosensitization via aptamer-shRNA chimeras in human tumor xenografts. J. Clin. Invest. 121, 2383-2390. doi: 10.1172/JCI45109 
Nikam, R. R., and Gore, K. R. (2018). Journey of siRNA: clinical developments and targeted delivery. Nucleic Acid Ther. 28, 209-224. doi: 10.1089/nat.2017.0715

Nikan, M., Osborn, M. F., Coles, A. H., Biscans, A., Godinho, B., Haraszti, R. A., et al. (2017). Synthesis and evaluation of parenchymal retention and efficacy of a metabolically stable O-phosphocholine-N-docosahexaenoyl-1serine siRNA conjugate in mouse brain. Bioconjug. Chem. 28, 1758-1766. doi: 10.1021/acs.bioconjchem.7b00226

Nikan, M., Osborn, M. F., Coles, A. H., Godinho, B. M., Hall, L. M., Haraszti, R. A., et al. (2016). Docosahexaenoic acid conjugation enhances distribution and safety of siRNA upon local administration in mouse brain. Mol. Ther. Nucleic Acids 5:e344. doi: 10.1038/mtna.2016.50

Nishina, K., Unno, T., Uno, Y., Kubodera, T., Kanouchi, T., Mizusawa, H., et al. (2008). Efficient in vivo delivery of siRNA to the liver by conjugation of alpha-tocopherol. Mol. Ther. 16, 734-740. doi: 10.1038/mt.2008.14

Ohrt, T., Mutze, J., Staroske, W., Weinmann, L., Hock, J., Crell, K., et al. (2008). Fluorescence correlation spectroscopy and fluorescence cross-correlation spectroscopy reveal the cytoplasmic origination of loaded nuclear RISC in vivo in human cells. Nucleic Acids Res. 36, 6439-6449. doi: 10.1093/nar/ gkn693

Ohrt, T., and Schwille, P. (2008). siRNA modifications and sub-cellular localization: a question of intracellular transport? Curr. Pharm. Des. 14, 3674-3685.

Oosenbrug, T., van de Graaff, M. J., Ressing, M. E., and van Kasteren, S. I. (2017). Chemical tools for studying TLR signaling dynamics. Cell Chem Biol. 24, 801-812. doi: 10.1016/j.chembiol.2017.05.022

Osborn, M. F., Coles, A. H., Biscans, A., Haraszti, R. A., Roux, L., Davis, S., et al. (2018). Hydrophobicity drives the systemic distribution of lipidconjugated siRNAs via lipid transport pathways. Nucleic Acids Res. 47, 10701081. doi: 10.1093/nar/gky1232

Ovaere, M., Herdewijn, P., and Van Meervelt, L. (2011). The crystal structure of the CeNA:RNA hybrid ce(GCGTAGCG):r(CGCUACGC). Chemistry. 17, 7823-7830. doi: 10.1002/chem.201003594

Park, J. H., and Shin, C. (2015). Slicer-independent mechanism drives smallRNA strand separation during human RISC assembly. Nucleic Acids Res. 43, 9418-9433. doi: 10.1093/nar/gkv937

Parker, N., Turk, M. J., Westrick, E., Lewis, J. D., Low, P. S., and Leamon, C. P. (2005). Folate receptor expression in carcinomas and normal tissues determined by a quantitative radioligand binding assay. Anal. Biochem. 338, 284-293. doi: 10.1016/j.ab.2004.12.026

Parrish, S., Fleenor, J., Xu, S., Mello, C., and Fire, A. (2000). Functional anatomy of a dsRNA trigger: differential requirement for the two trigger strands in RNA interference. Mol. Cell. 6, 1077-1087. doi: 10.1016/S1097-2765(00)00106-4

Pasternak, A., and Wengel, J. (2011). Unlocked nucleic acid-an RNA modification with broad potential. Org. Biomol. Chem. 9, 3591-3597. doi: 10.1039/c0ob01085e

Peacock, H., Kannan, A., Beal, P. A., and Burrows, C. J. (2011). Chemical modification of siRNA bases to probe and enhance RNA interference. J. Org. Chem. 76, 7295-7300. doi: 10.1021/jo2012225

Petrova Kruglova, N. S., Meschaninova, M. I., Venyaminova, A. G., Zenkova, M. A., Vlassov, V. V., and Chernolovskaya, E. L. (2010). 2'-O-methylmodified anti-MDR1 fork-siRNA duplexes exhibiting high nuclease resistance and prolonged silencing activity. Oligonucleotides. 20, 297-308. doi: 10.1089/oli.2010.0246

Pirher, N., Pohar, J., Mancek-Keber, M., Bencina, M., and Jerala, R. (2017). Activation of cell membrane-localized Toll-like receptor 3 by siRNA. Immunol. Lett. 189, 55-63. doi: 10.1016/j.imlet.2017.03.019

Pooga, M., Hallbrink, M., Zorko, M., and Langel, U. (1998). Cell penetration by transportan. FASEB J. 12, 67-77. doi: 10.1096/fasebj.12.1.67

Prakash, T. P., Allerson, C. R., Dande, P., Vickers, T. A., Sioufi, N., Jarres, R., et al. (2005). Positional effect of chemical modifications on short interference RNA activity in mammalian cells. J. Med. Chem. 48, 4247-4253. doi: $10.1021 / \mathrm{jm} 050044 \mathrm{o}$

Prakash, T. P., Lima, W. F., Murray, H. M., Li, W., Kinberger, G. A., Chappell, A. E., et al. (2015). Identification of metabolically stable $5^{\prime}$-phosphate analogs that support single-stranded siRNA activity. Nucleic Acids Res. 43, 2993-3011. doi: $10.1093 /$ nar/gkv162

Puthenveetil, S., Whitby, L., Ren, J., Kelnar, K., Krebs, J. F., and Beal, P. A. (2006). Controlling activation of the RNA-dependent protein kinase by siRNAs using site-specific chemical modification. Nucleic Acids Res. 34, 4900-4911. doi: $10.1093 / \mathrm{nar} / \mathrm{gkl} 464$

Rana, T. M. (2007). Illuminating the silence: understanding the structure and function of small RNAs. Nat. Rev. Mol. Cell Biol. 8, 23-36. doi: $10.1038 /$ nrm 2085

Ray, K. K., Landmesser, U., Leiter, L. A., Kallend, D., Dufour, R., Karakas, M., et al. (2017). Inclisiran in patients at high cardiovascular risk with elevated LDL cholesterol. N. Engl. J. Med. 376, 1430-1440. doi: 10.1056/NEJMoa1615758

Rozema, D. B., Blokhin, A. V., Wakefield, D. H., Benson, J. D., Carlson, J. C., Klein, J. J., et al. (2015). Protease-triggered siRNA delivery vehicles. J. Control. Release. 209, 57-66. doi: 10.1016/j.jconrel.2015.04.012

Rozema, D. B., Lewis, D. L., Wakefield, D. H., Wong, S. C., Klein, J. J., Roesch, P. L., et al. (2007). Dynamic PolyConjugates for targeted in vivo delivery of siRNA to hepatocytes. Proc. Natl. Acad. Sci. U.S.A. 104, 12982-12987. doi: $10.1073 /$ pnas. 0703778104

Sabatino, D., and Damha, M. J. (2007). Oxepane nucleic acids: synthesis, characterization, and properties of oligonucleotides bearing a seven-membered carbohydrate ring. J. Am. Chem. Soc. 129, 8259-8270. doi: 10.1021/ja071336c

Schirle, N. T., Kinberger, G. A., Murray, H. F., Lima, W. F., Prakash, T. P., and MacRae, I. J. (2016). Structural analysis of human argonaute-2 bound to a modified siRNA guide. J. Am. Chem. Soc. 138, 8694-8697. doi: 10.1021 /jacs.6b04454

Schirle, N. T., Sheu-Gruttadauria, J., and MacRae, I. J. (2014). Structural basis for microRNA targeting. Science. 346, 608-613. doi: 10.1126/science.1258040

Schlegel, M. K., Foster, D. J., Kel'in, A. V., Zlatev, I., Bisbe, A., Jayaraman, M., et al. (2017). Chirality dependent potency enhancement and structural impact of glycol nucleic acid modification on siRNA. J. Am. Chem. Soc. 139, 8537-8546. doi: 10.1021/jacs.7b02694

Schwarz, D. S., Tomari, Y., and Zamore, P. D. (2004). The RNA-induced silencing complex is a $\mathrm{Mg}^{2+}$-dependent endonuclease. Curr. Biol. 14, 787-791. doi: 10.1016/j.cub.2004.03.008

Schyth, B. D., Bramsen, J. B., Pakula, M. M., Larashati, S., Kjems, J., Wengel, J., et al. (2012). In vivo screening of modified siRNAs for non-specific antiviral effect in a small fish model: number and localization in the strands are important. Nucleic Acids Res. 40, 4653-4665. doi: 10.1093/nar/gks033

Selvam, C., Thomas, S., Abbott, J., Kennedy, S. D., and Rozners, E. (2011). Amides as excellent mimics of phosphate linkages in RNA. Angew. Chem. Int. Ed Engl. 50, 2068-2070. doi: 10.1002/anie.201007012

Sen, M., Thomas, S. M., Kim, S., Yeh, J. I., Ferris, R. L., Johnson, J. T., et al. (2012). First-in-human trial of a STAT3 decoy oligonucleotide in head and neck tumors: implications for cancer therapy. Cancer Discov. 2, 694-705. doi: 10.1158/2159-8290.CD-12-0191

Shen, W., De Hoyos, C. L., Sun, H., Vickers, T. A., Liang, X. H., and Crooke, S. T. (2018). Acute hepatotoxicity of 2' fluoro-modified 5-10-5 gapmer phosphorothioate oligonucleotides in mice correlates with intracellular protein binding and the loss of DBHS proteins. Nucleic Acids Res. 46, 2204-2217. doi: 10.1093/nar/gky060

Shen, W., Liang, X. H., Sun, H., and Crooke, S. T. (2015). 2'-Fluoro-modified phosphorothioate oligonucleotide can cause rapid degradation of P54nrb and PSF. Nucleic Acids Res. 43, 4569-4578. doi: 10.1093/nar/gkv298

Shen, X., and Corey, D. R. (2017). Chemistry, mechanism and clinical status of antisense oligonucleotides and duplex RNAs. Nucleic Acids Res. 46, 1584-1600. doi: 10.1093/nar/gkx1239

Shukla, R. S., Jain, A., Zhao, Z., and Cheng, K. (2016). Intracellular trafficking and exocytosis of a multi-component siRNA nanocomplex. Nanomedicine. 12, 1323-1334. doi: 10.1016/j.nano.2016.02.003

Sipa, K., Sochacka, E., Kazmierczak-Baranska, J., Maszewska, M., Janicka, M., Nowak, G., et al. (2007). Effect of base modifications on structure, thermodynamic stability, and gene silencing activity of short interfering RNA. RNA. 13, 1301-1316. doi: 10.1261/rna.538907

Snead, N. M., Escamilla-Powers, J. R., Rossi, J. J., and McCaffrey, A. P. (2013). 5 ' Unlocked nucleic acid modification improves siRNA targeting. Mol. Ther. Nucleic Acids 2:e103. doi: 10.1038/mtna.2013.36

Solomon, S. D., Adams, D., Kristen, A., Grogan, M., Gonzalez-Duarte, A., Maurer, M. S., et al. (2019). Effects of Patisiran, an RNA interference therapeutic, on cardiac parameters in patients with hereditary transthyretin-mediated amyloidosis. Circulation. 139, 431-443. doi: 10.1161/CIRCULATIONAHA.118.035831 
Somoza, A., Chelliserrykattil, J., and Kool, E. T. (2006). The roles of hydrogen bonding and sterics in RNA interference. Angew. Chem. Int. Ed Engl. 45, 4994-4997. doi: 10.1002/anie.200601311

Somoza, A., Silverman, A. P., Miller, R. M., Chelliserrykattil, J., and Kool, E. T. (2008). Steric effects in RNA interference: probing the influence of nucleobase size and shape. Chemistry. 14, 7978-7987. doi: 10.1002/chem.200800837

Song, E., Zhu, P., Lee, S. K., Chowdhury, D., Kussman, S., Dykxhoorn, D. M., et al. (2005). Antibody mediated in vivo delivery of small interfering RNAs via cell-surface receptors. Nat. Biotechnol. 23, 709-717. doi: 10.1038/ nbt1101

Song, X., Wang, X., Ma, Y., Liang, Z., Yang, Z., and Cao, H. (2017). Site-specific modification using the $2^{\prime}$-methoxyethyl group improves the specificity and activity of siRNAs. Mol. Ther. Nucleic Acids. 9, 242-250. doi: 10.1016/j.omtn.2017.10.003

Soutschek, J., Akinc, A., Bramlage, B., Charisse, K., Constien, R., Donoghue, M., et al. (2004). Therapeutic silencing of an endogenous gene by systemic administration of modified siRNAs. Nature. 432, 173-178. doi: 10.1038 /nature 03121

Spiess, M. (1990). The asialoglycoprotein receptor: a model for endocytic transport receptors. Biochemistry. 29, 10009-10018. doi: 10.1021/bi00495a001

Springer, A. D., and Dowdy, S. F. (2018). GalNAc-siRNA conjugates: leading the way for delivery of RNAi therapeutics. Nucleic Acid Ther. 28, 109-118. doi: 10.1089/nat.2018.0736

Subramanian, R. R., Wysk, M. A., Ogilvie, K. M., Bhat, A., Kuang, B., Rockel, T. D., et al. (2015). Enhancing antisense efficacy with multimers and multitargeting oligonucleotides (MTOs) using cleavable linkers. Nucleic Acids Res. 43, 9123-9132. doi: 10.1093/nar/gkv992

Sugahara, K. N., Teesalu, T., Karmali, P. P., Kotamraju, V. R., Agemy, L., Girard, O. M., et al. (2009). Tissue-penetrating delivery of compounds and nanoparticles into tumors. Cancer Cell. 16, 510-520. doi: 10.1016/j.ccr.2009. 10.013

Sugo, T., Terada, M., Oikawa, T., Miyata, K., Nishimura, S., Kenjo, E., et al. (2016). Development of antibody-siRNA conjugate targeted to cardiac and skeletal muscles. J. Control. Release. 237, 1-13. doi: 10.1016/j.jconrel.2016. 06.036

Sun, J., Pohl, E. E., Krylova, O. O., Krause, E., Agapov, I. I., Tonevitsky, A. G., et al. (2004). Membrane destabilization by ricin. Eur. Biophys. J. 33, 572-579. doi: 10.1007/s00249-004-0400-9

Takahashi, M., Contu, V. R., Kabuta, C., Hase, K., Fujiwara, Y., Wada, K., et al. (2017). SIDT2 mediates gymnosis, the uptake of naked singlestranded oligonucleotides into living cells. RNA Biol. 14, 1534-1543. doi: 10.1080/15476286.2017.1302641

Takahashi, M., Minakawa, N., and Matsuda, A. (2009). Synthesis and characterization of $2^{\prime}$-modified-4' ${ }^{\prime}$-thioRNA: a comprehensive comparison of nuclease stability. Nucleic Acids Res. 37, 1353-1362. doi: 10.1093/nar/gkn1088

Takahashi, M., Nagai, C., Hatakeyama, H., Minakawa, N., Harashima, H., and Matsuda, A. (2012). Intracellular stability of $2^{\prime}$-OMe- $4^{\prime}$-thioribonucleoside modified siRNA leads to long-term RNAi effect. Nucleic Acids Res. 40, 5787-5793. doi: 10.1093/nar/gks204

Terrazas, M., Alagia, A., Faustino, I., Orozco, M., and Eritja, R. (2013). Functionalization of the $3^{\prime}$-ends of DNA and RNA strands with N-ethyl-Ncoupled nucleosides: a promising approach to avoid $3^{\prime}$-exonuclease-catalyzed hydrolysis of therapeutic oligonucleotides. Chembiochem. 14, 510-520. doi: 10.1002/cbic.201200611

Terrazas, M., Ocampo, S. M., Perales, J. C., Marquez, V. E., and Eritja, R. (2011). Effect of north bicyclo[3.1.0]hexane 2'-deoxy-pseudosugars on RNA interference: a novel class of siRNA modification. Chembiochem. 12, 1056-1065. doi: 10.1002/cbic.201000791

Thomas, M., Kularatne, S. A., Qi, L., Kleindl, P., Leamon, C. P., Hansen, M. J., et al. (2009). Ligand-targeted delivery of small interfering RNAs to malignant cells and tissues. Ann. N. Y. Acad. Sci. 1175, 32-39. doi: $10.1111 / j .1749-6632.2009 .04977 . x$

Thoren, P. E., Persson, D., Karlsson, M., and Norden, B. (2000). The antennapedia peptide penetratin translocates across lipid bilayers-the first direct observation. FEBS Lett. 482, 265-268. doi: 10.1016/S0014-5793(00)02072-X

Tomari, Y., Matranga, C., Haley, B., Martinez, N., and Zamore, P. D. (2004). A protein sensor for siRNA asymmetry. Science. 306, 1377-1380. doi: $10.1126 /$ science. 1102755
Tu, Y., and Kim, J. S. (2008). A fusogenic segment of glycoprotein $H$ from herpes simplex virus enhances transfection efficiency of cationic liposomes. J. Gene Med. 10, 646-654. doi: 10.1002/jgm.1184

Turanov, A. A., Lo, A., Hassler, M. R., Makris, A., Ashar-Patel, A., Alterman, J. F., et al. (2018). RNAi modulation of placental sFLT1 for the treatment of preeclampsia. Nat. Biotechnol. 36, 1164-1173. doi: 10.1038/nbt.4297

Turner, A. M., Stolk, J., Bals, R., Lickliter, J. D., Hamilton, J., Christianson, D. R., et al. (2018). Hepatic-targeted RNA interference provides robust and persistent knockdown of alpha-1 antitrypsin levels in ZZ patients. J. Hepatol. 69, 378-384. doi: 10.1016/j.jhep.2018.03.012

Turner, J. J., Ivanova, G. D., Verbeure, B., Williams, D., Arzumanov, A. A., Abes, S., et al. (2005). Cell-penetrating peptide conjugates of peptide nucleic acids (PNA) as inhibitors of HIV-1 Tat-dependent trans-activation in cells. Nucleic Acids Res. 33, 6837-6849. doi: 10.1093/nar/gki991

Turner, J. J., Jones, S. W., Moschos, S. A., Lindsay, M. A., and Gait, M. J. (2007). MALDI-TOF mass spectral analysis of siRNA degradation in serum confirms an RNAse A-like activity. Mol. Biosyst. 3, 43-50. doi: 10.1039/b611612d

Ui-Tei, K., Naito, Y., Zenno, S., Nishi, K., Yamato, K., Takahashi, F., et al. (2008). Functional dissection of siRNA sequence by systematic DNA substitution: modified siRNA with a DNA seed arm is a powerful tool for mammalian gene silencing with significantly reduced off-target effect. Nucleic Acids Res. 36, 2136-2151. doi: 10.1093/nar/gkn042

Vaish, N., Chen, F., Seth, S., Fosnaugh, K., Liu, Y., Adami, R., et al. (2011). Improved specificity of gene silencing by siRNAs containing unlocked nucleobase analogs. Nucleic Acids Res. 39, 1823-1832. doi: 10.1093/nar/gkq961

van den Berg, A., and Dowdy, S. F. (2011). Protein transduction domain delivery of therapeutic macromolecules. Curr. Opin. Biotechnol. 22, 888-893. doi: 10.1016/j.copbio.2011.03.008

Varkouhi, A. K., Scholte, M., Storm, G., and Haisma, H. J. (2011). Endosomal escape pathways for delivery of biologicals. J. Control. Release 151, 220-228. doi: 10.1016/j.jconrel.2010.11.004

Viel, T., Boisgard, R., Kuhnast, B., Jego, B., Siquier-Pernet, K., Hinnen, F., et al. (2008). Molecular imaging study on in vivo distribution and pharmacokinetics of modified small interfering (siRNAs). Oligonucleotides. 18, 201-212. doi: 10.1089/oli.2008.0133

Vives, E., Brodin, P., and Lebleu, B. (1997). A truncated HIV-1 Tat protein basic domain rapidly translocates through the plasma membrane and accumulates in the cell nucleus. J. Biol. Chem. 272, 16010-16017. doi: 10.1074/jbc.272.25. 16010

Vlaho, D., Fakhoury, J. F., and Damha, M. J. (2017). Structural studies and gene silencing activity of siRNAs containing cationic phosphoramidate linkages. Nucleic Acid Ther. 28, 34-43. doi: 10.1089/nat.2017.0702

Volkov, A. A., Kruglova, N. S., Meschaninova, M. I., Venyaminova, A. G., Zenkova, M. A., Vlassov, V. V., et al. (2009). Selective protection of nucleasesensitive sites in siRNA prolongs silencing effect. Oligonucleotides. 19, 191-202. doi: $10.1089 /$ oli.2008.0162

Wadia, J. S., Stan, R. V., and Dowdy, S. F. (2004). Transducible TAT-HA fusogenic peptide enhances escape of TAT-fusion proteins after lipid raft macropinocytosis. Nat. Med. 10, 310-315. doi: 10.1038/nm996

Wang, J., Verbeure, B., Luyten, I., Froeyen, M., Hendrix, C., Rosemeyer, H., et al. (2001). Cyclohexene nucleic acids (CeNA) form stable duplexes with RNA and induce RNase H activity. Nucleosides Nucleotides Nucleic Acids. 20, 785-788. doi: $10.1081 / \mathrm{NCN}-100002430$

Wang, S., Allen, N., Vickers, T. A., Revenko, A. S., Sun, H., Liang, X. H., et al. (2018). Cellular uptake mediated by epidermal growth factor receptor facilitates the intracellular activity of phosphorothioate-modified antisense oligonucleotides. Nucleic Acids Res. 46, 3579-3594. doi: 10.1093/nar/gky145

Weis, S. M., and Cheresh, D. A. (2011). alphaV integrins in angiogenesis and cancer. Cold Spring Harb. Perspect. Med. 1:a006478. doi: $10.1101 /$ cshperspect.a006478

Weitzer, S., and Martinez, J. (2007). The human RNA kinase hClp1 is active on $3^{\prime}$ transfer RNA exons and short interfering RNAs. Nature. 447, 222-226. doi: $10.1038 /$ nature 05777

Whitehead, K. A., Langer, R., and Anderson, D. G. (2009). Knocking down barriers: advances in siRNA delivery. Nat. Rev. Drug Discov. 8, 129-138. doi: $10.1038 / \mathrm{nrd} 2742$

Willoughby, J. L. S., Chan, A., Sehgal, A., Butler, J. S., Nair, J. K., Racie, T., et al. (2018). Evaluation of GalNAc-siRNA conjugate activity in pre-clinical animal 
models with reduced asialoglycoprotein receptor expression. Mol. Ther. 26, 105-114. doi: 10.1016/j.ymthe.2017.08.019

Wolfrum, C., Shi, S., Jayaprakash, K. N., Jayaraman, M., Wang, G., Pandey, R. $\mathrm{K}$., et al. (2007). Mechanisms and optimization of in vivo delivery of lipophilic siRNAs. Nat. Biotechnol. 25, 1149-1157. doi: 10.1038/nbt1339

Wong, S. C., Klein, J. J., Hamilton, H. L., Chu, Q., Frey, C. L., Trubetskoy, V. S., et al. (2012). Co-injection of a targeted, reversibly masked endosomolytic polymer dramatically improves the efficacy of cholesterolconjugated small interfering RNAs in vivo. Nucleic Acid Ther. 22, 380-390. doi: $10.1089 /$ nat.2012.0389

Wooddell, C. I., Rozema, D. B., Hossbach, M., John, M., Hamilton, H. L., Chu, Q., et al. (2013). Hepatocyte-targeted RNAi therapeutics for the treatment of chronic hepatitis B virus infection. Mol. Ther. 21, 973-985. doi: $10.1038 / \mathrm{mt} .2013 .31$

Wooddell, C. I., Yuen, M. F., Chan, H. L., Gish, R. G., Locarnini, S. A., Chavez, D., et al. (2017). RNAi-based treatment of chronically infected patients and chimpanzees reveals that integrated hepatitis B virus DNA is a source of HBsAg. Sci. Transl. Med. 9:eaan0241. doi: 10.1126/scitranslmed.aan0241

Xia, C. F., Boado, R. J., and Pardridge, W. M. (2009). Antibody-mediated targeting of siRNA via the human insulin receptor using avidin-biotin technology. Mol. Pharm. 6, 747-751. doi: 10.1021/mp800194y

Xia, C. F., Zhang, Y., Boado, R. J., and Pardridge, W. M. (2007). Intravenous siRNA of brain cancer with receptor targeting and avidin-biotin technology. Pharm. Res. 24, 2309-2316. doi: 10.1007/s11095-007-9460-8

Xia, W., and Low, P. S. (2010). Folate-targeted therapies for cancer. J. Med. Chem. 53, 6811-6824. doi: $10.1021 / \mathrm{jm} 100509 \mathrm{v}$

Yan, A. C., and Levy, M. (2018). Aptamer-mediated delivery and celltargeting aptamers: room for improvement. Nucleic Acid Ther. 28, 194-199. doi: 10.1089/nat.2018.0732

Yang, J., Chen, C., and Tang, X. (2018). Cholesterol-modified caged siRNAs for photoregulating exogenous and endogenous gene expression. Bioconjug. Chem. 29, 1010-1015. doi: 10.1021/acs.bioconjchem.8b00080

Yvan-Charvet, L., Pagler, T. A., Wang, N., Senokuchi, T., Brundert, M., Li, H., et al. (2008). SR-BI inhibits ABCG1-stimulated net cholesterol efflux from cells to plasma HDL. J. Lipid Res. 49, 107-114. doi: 10.1194/jlr.M700200-JLR200
Zanardi, T. A., Kim, T. W., Shen, L., Serota, D., Papagiannis, C., Park, S. Y., et al. (2018). Chronic toxicity assessment of 2'-O-methoxyethyl antisense oligonucleotides in mice. Nucleic Acid Ther. 28, 233-241. doi: 10.1089/nat.2017.0706

Zatsepin, T. S., Kotelevtsev, Y. V., and Koteliansky, V. (2016). Lipid nanoparticles for targeted siRNA delivery-going from bench to bedside. Int. J. Nanomedicine. 11, 3077-3086. doi: 10.2147/IJN.S106625

Zhang, Q., Hossain, D. M., Duttagupta, P., Moreira, D., Zhao, X., Won, H., et al. (2016). Serum-resistant CpG-STAT3 decoy for targeting survival and immune checkpoint signaling in acute myeloid leukemia. Blood. 127, 1687-1700. doi: 10.1182/blood-2015-08665604

Zhang, Q., Hossain, D. M., Nechaev, S., Kozlowska, A., Zhang, W., Liu, Y., et al. (2013). TLR9-mediated siRNA delivery for targeting of normal and malignant human hematopoietic cells in vivo. Blood. 121, 1304-1315. doi: 10.1182/blood-2012-07-442590

Zhou, J., and Rossi, J. (2017). Aptamers as targeted therapeutics: current potential and challenges. Nat. Rev. Drug Discov. 16, 181-202. doi: 10.1038/nrd. 2016.199

Zimmermann, T. S., Karsten, V., Chan, A., Chiesa, J., Boyce, M., Bettencourt, B. R., et al. (2017). Clinical proof of concept for a novel hepatocyte-targeting GalNAc-siRNA conjugate. Mol. Ther. 25, 71-78. doi: 10.1016/j.ymthe.2016. 10.019

Conflict of Interest Statement: The authors declare that the research was conducted in the absence of any commercial or financial relationships that could be construed as a potential conflict of interest.

Copyright $\odot 2019$ Chernikov, Vlassov and Chernolovskaya. This is an open-access article distributed under the terms of the Creative Commons Attribution License (CC $B Y)$. The use, distribution or reproduction in other forums is permitted, provided the original author(s) and the copyright owner(s) are credited and that the original publication in this journal is cited, in accordance with accepted academic practice. No use, distribution or reproduction is permitted which does not comply with these terms. 